\title{
Tongue immune compartment analysis reveals spatial macrophage heterogeneity
}

Ekaterini Maria Lyras ${ }^{1}$, Karin Zimmermann ${ }^{1}$, Lisa Katharina Wagner ${ }^{1}$, Dorothea Dörr ${ }^{1,2}$, Cornelius Fischer ${ }^{1}$, Steffen Jung ${ }^{3}$, Simon Yona ${ }^{4}$, Avi-Hai Hovav ${ }^{4}$, Werner Stenzel ${ }^{5}$, Steffen Dommerich $^{6}$, Thomas Conrad ${ }^{1}$, Achim Leutz $^{1,2}$ and Alexander Mildner ${ }^{1,7}$

${ }^{1}$ Max-Delbrück-Center for Molecular Medicine (MDC), Berlin, Germany.

${ }^{2}$ Institute of Biology, Humboldt University of Berlin, Berlin, Germany

${ }^{3}$ Weizmann Institute of Science, Rehovot, Israel

${ }^{4}$ Institute of Dental Sciences, Hebrew University, Jerusalem, Israel

${ }^{5}$ Department of Neuropathology, Charité Berlin, Berlin, Germany

${ }^{6}$ Department of Otorhinolaryngology, Charité Berlin, Berlin, Germany

${ }^{7}$ InFLAMES Research Flagship Center, University of Turku

Correspondence: Alexander.Mildner@utu.fi 


\begin{abstract}
The tongue is a unique muscular organ situated in the oral cavity where it is involved in taste sensation, mastication and articulation. As a barrier organ, which is constantly exposed to environmental pathogens, the tongue is expected to host an immune cell network ensuring local immune defence. However, the composition and the transcriptional landscape of the tongue immune system are currently not completely defined. Here we characterised the tissue-resident immune compartment of the murine tongue during development, health and disease, combining single cell RNA-sequencing with in situ immunophenotyping. We identified distinct local immune cell populations and described two specific subsets of tongue-resident macrophages occupying discrete anatomical niches. $\mathrm{C} \times 3 \mathrm{cr}^{+}$macrophages were located specifically in the highly innervated lamina propria beneath the tongue epidermis and at times in close proximity to fungiform papillae. Folr ${ }^{+}$macrophages were detected in deeper muscular tissue. The two macrophage subsets originate from a common proliferative precursor during early postnatal development and responded differently to systemic LPS in vivo. Our description of the under-investigated tongue immune system sets a starting point to facilitate research on tongue immune-physiology and pathology including cancer and taste disorders.
\end{abstract}




\section{Introduction}

The tongue is a highly innervated muscular organ with functions in articulation, mastication and taste perception. Located at the entrance of the gastrointestinal tract, the tongue is constantly exposed to dietary and airborne antigens and therefore acts as a firstline immune organ ${ }^{1}$. Moreover, taste sensation plays a critical role in avoidance of spoiled food and beverages. Accordingly, a tongue-resident immune network would be expected with roles in immune defense, tissue remodeling and tongue homeostasis. However, in the immunological context, the tongue is an understudied organ and the composition of tongue immune cells and their transcriptional status is largely unknown. Here, we define the immune cell landscape of the tongue with a specific focus on mononuclear phagocytes, e.g. tissueresident macrophages (TRM).

Until now, the characterization of the mononuclear phagocyte compartment of the tongue mainly focused on Langerhans cells that were first described in the mouse epithelium forty years ago ${ }^{2}$ and are identified in humans by their exclusive CD1a immunoreactivity ${ }^{3,4}$. The characterization of sub-epithelial macrophage subsets is much more enigmatic and so far depended on the histological examination of a few membrane markers ${ }^{5,6}$. For example, human $\mathrm{CD}_{163^{+}}$macrophages can be found in subepithelial areas of the tongue ${ }^{6}$, a localization that they share with CD11 $\mathrm{c}^{+}$"dendritic" cells ${ }^{7}$. Relying on single markers such as CD11c to identify cells of the "dendritic" cell lineage is problematic since various additional cell types, including monocytes, macrophages and lymphocytes, can express CD11c ${ }^{8}$. Besides histological examinations of mononuclear phagocytes in the healthy tongue, the macrophage involvement in various pathological settings has also been studied. Tongue Langerhans cells were for instance shown to be critically involved in IL17-dependent antifungal immunity in the oral mucosa ${ }^{9}$, play an important role in $\mathrm{T}$ cell priming during squamous cell carcinoma development ${ }^{10}$ and are depleted in patients with advanced-stage acquired immune deficiency syndrome ${ }^{11}$. Furthermore, an increase of activated ED $1^{+}$ tongue macrophages was observed in systemic inflammation in rats ${ }^{12}$. The recent COVID19 pandemic has also suggested a potential link of viral infections with tongue immunity, with loss of taste being one of the hallmark symptoms ${ }^{13}$. However, the lack of knowledge of the tongue immune cell compartment in physiology, hampers our understanding of tongue immune responses following pathogen challenge. Therefore, an unbiased characterization of the tongue immune cells is critical to classify and evaluate tissue-resident cell subsets, e.g. macrophage dynamics during tongue development and pathologies.

To this end, we profiled the tongue-resident $\mathrm{CD} 45^{+}$hematopoietic cell compartment by single cell RNA-sequencing (scRNA-seq). Amongst tongue innate lymphoid cells, e.g. 
ILC2, and the specific presence of mast cells in early postnatal tongues, we further identified two main Irf8-independent macrophage populations, which were characterized by $\mathrm{C} \times 3 \mathrm{cr} 1$ and Folr2 expression, respectively. Cx3cr1-expressing macrophages were specifically enriched in the lamina propria of the tongue and were detected in fungiform papillae, which harbor taste buds, but were absent from the epidermis. Folr2-expressing tongue macrophages localized in muscular tissue and in the lamina propria. These anatomical niches were colonized during embryonic and early postnatal development from a $\mathrm{C} \times 3 \mathrm{cr} 1$ expressing precursor of high proliferation capacity. Both macrophage populations showed a robust inflammatory response after in vivo lipopolysaccharide (LPS) administration, including shared and unique pathways.

In summary, our data provide a detailed atlas of the immune cells of the tongue that will facilitate future research of this under-investigated barrier organ. 


\section{Results}

\section{Characterization of murine tongue hematopoietic cells}

To examine the tissue-resident immune compartment of the tongue in an unbiased manner, we performed scRNA-seq of FACS-purified $\mathrm{CD}_{4} 5^{+}$hematopoietic tongue cells isolated from PBS-perfused adult wild-type C57BL/6 mice. Two biologically and technically independent 10X Chromium experiments were performed that yielded highly reproducible results (Suppl. Fig. 1a+b).

We sequenced a total of 6773 cells that clustered into 19 transcriptionally distinct subsets (Fig. 1a+b) and used singleR ${ }^{14}$ for cell lineage recognition (Suppl. Fig. 1c). A full list of marker genes and average expression values per cluster can be found in Suppl. Data 1+2. We detected type 2 innate lymphoid cells (cluster 9: ILC2 defined by Gata3, Rora, Ctla2 and Arg1), regulatory T cells (cluster 4; characterized by Ikzf2, Tnfrsf18, Cd3d and Cd28), Rora $^{+} \mathrm{T}$ cells (cluster 17; characterized by Cd3e, Lck, Cd28 and II2rb), natural killer cells (cluster 14; defined by $C d 3 d, N k g 7, K I r d 1, \quad X c / 1$ expression), B cells (cluster 12; characterized by Cd79a and Cd19), mast cells (clusters 11 and 13; defined by Kit and Ms4a2), neutrophils (cluster 8; defined by S100a9 and Retnlg), a few endothelial cells (cluster 16, which is mainly present in subsequent scRNA-seq analysis of Fig.3; defined by Aqp1, Col4a1 and Pecam1), fibroblasts (cluster 19; defined by Dcn, Peg3, Cald1), and small clusters of proliferating precursor cells (Mki67, Mcm gene family and Top2a; clusters 7, 14 and 16$)$. However, the majority of cells $(65 \%)$ fell into the broad category of mononuclear phagocytes and included Langerhans cells (defined by Epcam and Cd9 expression; cluster 10), different classical dendritic cell (cDC) subsets (cluster 3, 15, 18 and 6), monocytes (characterized by Ly6c2, Cebpb, Nr4a1 expression; cluster 6) and three subsets of Cd68expressing macrophages (clusters 0, 1 and 5).

As mononuclear phagocytes would be the first responders in tongue immunity, we focused our subset analysis on this major cell compartment. First, we separated mononuclear phagocytes into macrophages and dendritic cells (DC). For this, we performed a gene set variation analysis (GSVA) ${ }^{15}$ by taking advantage of published CDC and macrophage gene signatures ${ }^{16,17}$ (Suppl. Data 3). The transcriptional signature of clusters 3 , 15 and 18 correlated with the CDC gene signature (Fig. 1b) and they could further be separated into CDC1 (cluster 3; defined by Cd209a, Cd24a and Irf8) and DC precursors (clusters 15 and 18; characterized by Hmgb2, Asf1b, Atad2). While singleR annotated the Fn1, Lpl, Ear2 expressing cells with MHCll-related gene expression in cluster 6 as CD11 $\mathrm{b}^{+}$ DCs (Suppl. Fig. 1c), these cells had neither a strong DC nor a strong macrophage signature (Fig. 1b). As the specific $\mathrm{cDC} 2$ gene signature ${ }^{17}$ was also absent in this cluster (Suppl. Fig. 1d), the precise ontogeny of these cells will need further investigation. 
The GSVA analysis revealed three clusters of cells with macrophage identity, of which clusters 0 and 5 are likely end-stage differentiated macrophage subsets (Fig. 1b). Cells in the third macrophage cluster (cluster 1) seem to be macrophages of intermediate differentiation, as their transcriptomic signature shares features with both cluster 0 and 5 (Fig. $1 \mathbf{c}+\mathbf{d}$ ). Of the two terminally differentiated macrophage clusters, cluster 0 (hereafter referred to as tFOLR2-MF) expressed high levels of Folr2, Lyve1, Pf4 and Timd4, while cluster 5 (hereafter referred to as tCX3CR1-MF) expressed high levels of Cx3cr1, Hexb, Ms4a7, Itgax and Pmepa1 (Fig. 1c+d). A pairwise comparison of tFOLR2-MF and tCX3CR1-MF transcriptomes revealed 602 differentially expressed genes (DEGs), indicating major differences between the two tongue macrophage populations $(\mathrm{abs}(\mathrm{FC})>1.5$ and adjusted $\mathrm{p}$ value < 0.05) (Fig. 1e). Both tCX3CR1-MF and tFOLR2-MF were transcriptionally distinct from tongue Langerhans cells (tLCs; Fig. 1e), which rather fell under the CDC signature (Fig. 1b)

We performed gene ontology (GO) enrichment analysis for the different mononuclear phagocyte clusters to gather information on possible distinct functions of these transcriptionally defined cell subtypes. Marker genes of intermediate clusters 1, 3 and 6 were not particularly enriched for any GO biological processes, which potentially reflects their intermediate gene expression signature (Fig. 1e; the full list of GO annotation is listed in Suppl. Data 4). tFOLR2-MF on the other hand were enriched for gene sets associated with blood vessel biology ("regulation of sprouting angiogenesis") and macrophage function ("cytosolic transport", "macrophage differentiation" and "positive regulation of nitric oxide biosynthesis"); tCX3CR1-MF showed gene enrichment for broad immune biological processes such as "positive regulation of ERK1/2 cascade" or "TLR3 signalling pathway" and exhibited similarities to CNS-resident microglia with gene enrichment in the biological process "microglial cell proliferation" (Fig. 1f).

Recent studies have indicated potential interactions of Cx3cr1-expressing macrophages with neurons ${ }^{18-20}$. However, unlike these $\mathrm{CX}_{3} \mathrm{CR} 1^{+}$brown adipose tissue and skin nerve-associated macrophages ${ }^{18-20}$, we did not detect a specific and significant enrichment for genes involved in axon guidance, such as Plexina4 in tCX3CR1-MF (Suppl. Fig. 1e).

Altogether, our scRNA-seq data show that the tongue harbours a wide range of tissue-resident immune cells, of which the majority belong to the mononuclear phagocyte system. We identified two terminally differentiated macrophage subsets: tCX3CR1-MF that have a transcriptomic signature associated with innate immune signaling and tFOLR2-MF that seem to function in blood vessel biology and phagocytosis. 


\section{Tongue macrophages belong to the family of interstitial macrophages}

We next established a protocol for the identification and isolation of tCX3CR1-MF and tFOLR2-MF by flow cytometry in $\mathrm{C} \times 3 \mathrm{cr} 1^{\mathrm{Gfp} /+}$ reporter mice ${ }^{21}$. After DNase/Collagenase IV/Hyaluronidase digestion of the tongue (Suppl. Fig. 2a), we were able to detect CD64 ${ }^{+}$ cells that could further be separated into cells expressing high levels of Cx3cr1-GFP (tCX3CR1-MF) and cells that stained positive for Folr2 (tFOLR2-MF; Fig. 2a). tCX3CR1-MF also expressed the surface receptors $\mathrm{CX}_{3} \mathrm{CR} 1, \mathrm{~F} 4 / 80, \mathrm{MHCI}$ and $\mathrm{CD} 11 \mathrm{c}$, while tFOLR2-MF were additionally characterized by LYVE1 and TIMD4 expression (Fig. 2b). These surface characteristics could also be used to identify the tCX3CR1-MF and tFOLR2-MF in WT BI6 animals.

To identify tongue-specific signatures of tCX3CR1-MF and tFOLR2-MF and to place them in the context of macrophage biology, we compared the transcriptional profiles of FACS-purified tongue macrophages with macrophages isolated from other tissues. We FACS-isolated microglia from the brain, alveolar macrophages from the lung (lung AM), heart $\mathrm{MHClI}^{+}$and $\mathrm{MHCll}^{-} \mathrm{C} \times 3 \mathrm{cr} 1-\mathrm{Gfp}^{+}$macrophages, $\mathrm{MHClI}^{+}$intestinal macrophages (colon MF) and $\mathrm{F} 4 / 80^{+}$splenic red pulp macrophages (spleen RPM; see Suppl. Fig. 3 for gating strategy and Suppl. Data 5 for full read count table). We additionally sorted skin and tongue Langerhans cells for comparison (sLC and tLC, respectively). Of note, a different digestion protocol was necessary to isolate Epcam ${ }^{+}$tLCs from the epithelial layer of the tongue (Suppl. Fig. 2b).

To validate the data quality, we compared expression of common macrophagerelated genes in the different macrophage populations (Fig. 2c). All cells except Langerhans cells expressed the macrophage genes Cd68, Mertk and Fcgr1. Furthermore, Csf1r expression was detected in almost all macrophage subsets with particularly high levels in microglia, but not in alveolar macrophages ${ }^{16}$. Cx3cr1, Lyve1 or MHCll-related genes such as Cd74 were also expressed according to the expected expression pattern (Fig. 2c), which confirmed the accuracy of our gating and sorting strategy.

Correlation analysis of all macrophage populations revealed that, in line with published data ${ }^{14,22}$, classical TRM populations such as microglia, splenic macrophages, Langerhans cells and alveolar macrophages each had a very distinct expression profile, indicating the robust tissue imprinting of these cells (Fig. $\mathbf{2 d}$ ). Tongue macrophages on the other hand were more related to heart and intestinal macrophages, regardless of their tissue of residence. Morover, even within this group of TRM, MHCIl expressing cells like heart $\mathrm{MHCII}^{+}$macrophages, tCX3CR1-MF and colon macrophages showed a higher correlation to each other and were distinct from $\mathrm{MHCll}^{-}$cell populations, including tFOLR2-MF and heart $\mathrm{MHCII}^{+}$macrophages (Fig. 2d). Thus, tCX3CR1-MF and tFOLR2-MF share similarities with 
the two main interstitial macrophage populations that have been previously identified across various tissues ${ }^{19,22}$

We focused our analysis on up-regulated genes ( $F C>2$; adjusted $p$-value $<0,001)$ to identify a tissue-specific signature of each macrophage subset and were able to annotate previously described marker genes to macrophage populations isolated from the lung, heart, skin, brain and spleen ${ }^{16,23}$. tCX3CR1-MF on the other hand expressed significantly higher levels of II2ra, II1a and Irak2 compared to all other tested TRM subsets, while tFOLR2-MF were characterized by the transcription of Cd209 gene family members (Cd209b/d/f), Retnla, Clec10a and Fxyd2. The top genes for each macrophage subset are shown as a heatmap in Fig. 2e and a full list of these up-regulated genes can be found in Suppl. Data 6.

We next performed a GO enrichment analysis on these DEGs and found in agreement with previously published work ${ }^{24}$ an enrichment of $\mathrm{GO}$ terms that facilitate the tissue-specific function of each TRM subset (Fig. 2f). In comparison, tCX3CR1-MF showed a strong enrichment for genes involved in inflammatory pathways, such 'positive regulation of TNF production' or 'cytokine-mediated signaling pathway', which is in line with our scRNAseq data presented in Fig. 1. tFOLR2-MF were characterized by weak but significant enrichment for 'cellular hyperosmotic salinity response' and 'response to toxic substances'.

Taken together, these data demonstrate that tCX3CR1-MF and tFOLR2-MF tongue macrophages belong to the family of interstitial macrophages. They fall into the two broad categories of Cx3cr1- and Lyve1/Folr2/Timd4-expressing cells ${ }^{19,22}$, but also show unique transcriptomic signatures that probably reflect the requirements of their local tissue niche.

\section{Distinct localizations of tCX3CR1- and tFOLR2-macrophages in the adult tongue}

The unique transcriptomic signatures of tCX3CR1-MF and tFOLR2-MF could indicate that these populations inhabit different microanatomical niches within the tongue. To test this hypothesis, we performed immunohistochemistry on adult mouse tongues. $C \times 3 c r 1^{\mathrm{Gfp} /+}$ animals were perfused and fixed tongue sections were stained with antibodies against GFP and LYVE1. Of note, we have used LYVE1 and FOLR2 markers interchangeably for the identification of tFOLR2-MF. Indeed, $\mathrm{GFP}^{+}$cells were concentrated in the lamina propria, while LYVE1 staining was evident on cells throughout the tongue tissue with the exception of the epidermis (Fig. $\mathbf{3 a + b}$ ). Since lymphatic vessels also stain positive for LYVE1 ${ }^{25}$, the tissue was counterstained with antibody against CD68, a common pan-macrophage marker. Thus, we could identify tCX3CR1-MF as double-positive $\mathrm{CD}^{+} 8^{+} \mathrm{C} \times 3 \mathrm{cr} 1-\mathrm{GFP}^{+}$cells in the lamina propria, but not in the tongue epidermis or muscle (Fig. 3c) and tFOLR2-MF as double-positive CD68 ${ }^{+} \mathrm{LYVE} 1^{+}$cells in the lamina propria and the underlying muscle (Fig. 3d). Of note, tFOLR2-MF were morphologically distinct from LYVE1 ${ }^{+}$Podoplanin ${ }^{+}$lymphatics 
(Fig. 3e). EPCAM ${ }^{+}$Langerhans cells with a ramified morphology localized exclusively in the epidermis of the tongue (Fig. $\mathbf{3 f}$ ).

To better characterize the tissue localisation of tCX3CR1-MF and tFOLR2-MF, we quantified their distribution in different layers of the tongue. $C D 68^{+} L Y V E 1^{+}$double-positive tFOLR2-MF localized in the muscular layer as well as in the lamina propria (Fig. $\mathbf{3 g} \mathbf{h}$ and Suppl. Fig. 4), while $\mathrm{CD}^{+} 8^{+} \mathrm{C} \times 3 \mathrm{cr} 1-\mathrm{GFP}^{+}$double-positive tCX3CR1-MF were only detected in the lamina propria and were virtually absent in muscular tissue (Fig. 3g). However, clusters of $\mathrm{Cx} 3 \mathrm{cr} 1-\mathrm{GFP}^{+}$cells could be detected in the posterior part of the tongue, along Tuj $1^{+}$nerves that possibly cater to circumvallate and foliate papillae (Fig. 3i) and in innervated areas of the deep muscle, along the chorda tympani branch of the facial nerve. tCX3CR1-MF were present at the base of both filiform and fungiform papillae (which harbour taste buds) and within the lamina propria, which is densely innervated by sensory fibres (Fig. $3 \mathbf{j}+\mathbf{k})$.

Thus, we show here that tongue tCX3CR1-MF and tFOLR2-MF inhabit distinct anatomical regions of the tongue. ICX3CR1-MF localized in the highly innervated lamina propria at the base of filiform papillae and within fungiform papillae, while tFOLR2-MF can additionally be found in deeper layers, often in proximity to blood vessels.

\section{Response of tongue macrophages to systemic inflammation}

Regardless of their tissue-specific roles in homeostasis, macrophages usually also function as first-line responders to pathogens. We therefore tested the inflammatory response of tongue immune cells to the bacteria endotoxin lipopolysaccharide (LPS). Mice were challenged intraperitoneally (i.p.) with LPS and transcriptomic changes of the tongue hematopoietic system (CD45 ${ }^{+}$cells) were determined by scRNA-seq $6 \mathrm{~h}$ later. In total, we sequenced 8165 cells. Integration of the LPS data with the data from steady state mice indicated that all cell populations were present 6 hours after LPS injection (Fig. 4a). LPS injection led to a general increase of inflammatory gene expression such as Oas/1 and Ifi204 across all cells of the tongue immune system (Fig. 4b).

We focused on tongue-resident macrophages of cluster 0 (tFOLR2-MF) and cluster 5 (tCX3CR1-MF) and examined DEGs between the steady state and LPS conditions in these two populations. 211 DEGs were identified in tFOLR2-MF (the full list of DEGs can be found in Suppl. Data 7), of which 125 genes were upregulated (e.g. $/ 11 b$, Relb and S/fn4) and 86 genes downregulated after LPS injection (e.g. Folr2, Lyve1 and Klf4; Fig. 4c+d). Interestingly, many of the tFOLR2-MF signature genes (i.e. Folr2 and Lyve1) were downregulated after LPS exposure (Fig. 4c). In tCX3CR1-MF we detected 127 DEGs between the physiological and the pathological state of which 84 were upregulated (e.g. Ifit2, Lgals3 and Usp18) and 43 were downregulated (e.g. Lyz2, Ccr2 and Cd9). LPS induced upregulation of 45 common 
genes (e.g. Cxc/10, Ccl5, I/1rn and Gbp2) and downregulation of 17 common genes in both tongue macrophage subsets (e.g. Fcrls, S100a10, Lyz1 and Retnla; Fig. 4c+d).

GO enrichment analysis was used to explore potential signaling differences of tFOLR2-MF and tCX3CR1-MF in response to systemic LPS. Shared upregulated genes in the two subsets were involved in 'defense response', 'response to cytokine' and 'response to bacterium'. Genes that were only upregulated in tCX3CR1-MF macrophages were particularly enriched for GO terms associated with type I interferon signaling (Fig. 4e). On the other hand, tCX3CR1-MF showed downregulation of genes involved in 'mononuclear cell migration' and 'cell population proliferation' after LPS exposure (Fig. 4e). tFOLR2-MF showed the specific upregulation of genes involved in ,immune system process' and ,Nfkb signaling', while they downregulated in response to LPS the 'response to stress', ,localisation of cell' apoptotic processes.

Thus, both tFOLR2-MF and tCX3CR1-MF were activated by systemic administration of bacterial components (LPS). However, they responded differently, with strong type I interferon signaling response characterizing $\mathrm{tCX}{ }_{3} \mathrm{CR} 1-\mathrm{MF}$ and a more 'classical' Nfkbmediated macrophage response seen in tFOLR2-MF.

\section{Distribution and subset analysis of tongue macrophages during development}

We next investigated the spatiotemporal distribution of tongue macrophages over development in an effort to shed light on the origin and timeline of establishment of tFOLR2MF and $\mathrm{tCX} 3 \mathrm{CR} 1-\mathrm{MF}$ populations. First, we isolated leukocytes from $\mathrm{C} \times 3 \mathrm{cr} 1^{\mathrm{Gfp} /+}$ reporter mice at different ages and performed flow cytometry to detect $\mathrm{CD} 11 \mathrm{~b}^{+} \mathrm{CD} 64^{+}$macrophages that we could further separate according to $C \times 3 c r 1-G F P$ expression and FOLR2 immunoreactivity. We used FOLR2 as a marker since macrophages at this developmental stage do not show LYVE1 surface expression. At embryonic day 17.5 (E17.5), all tongue macrophages were characterized by high Cx3cr1-GFP expression (Fig. 5a). Of these Cx3cr1-GFP ${ }^{+}$cells, two-thirds additionally expressed FOLR2 (G2 in Fig. 5a). Similar proportions of macrophage subsets were observed in the mouse tongue at postnatal day 3 (p3). At this time-point, an intermediate $C \times 3 c r 1-G F P^{\text {int }}$ FOLR2 ${ }^{+}$subset was also present (G3 in Fig. 5a+b). In subsequent developmental stages ( $\mathrm{p} 11$ and p28), the proportion of doublepositive $\mathrm{C} \times 3 \mathrm{cr} 1-\mathrm{GFP}^{+} \mathrm{FOLR}^{+}$cells progressively decreased and two main $\mathrm{C} \times 3 \mathrm{cr} 1-$ GFP $^{+}$FOLR2 $^{-}$and $C \times 3 c r 1-G F P^{\text {int }} F \mathrm{OLR}^{+}$macrophage populations (corresponding to tCX3CR1-MF and tFOLR2-MF respectively) were established by 8 weeks of age (Fig. $5 \mathbf{b}$ ).

To correlate the flow cytometry data to spatial localization, we performed immunohistochemical analysis of tongue sections from $C \times 3 c r 1^{\mathrm{Gfp} /+}$ mice during early developmental stages. As mentioned above, tongue macrophages did not express Lyve1 during development and the FOLR2 antibody used for FACS did not work for 
immunohistochemical staining of the tissue. We thus relied on Cx3cr1-GFP as a marker of macrophages. Tissue sections were counterstained with antibodies against CD31 to identify blood vessels, and, since various nerves (e.g. VII ${ }^{\text {th }}, I X^{\text {th }}$ and $X^{\text {th }}$ cranial nerve ganglia) innervate the tongue tissue during embryogenesis, we also stained tissue sections for antibeta Tubulin III (Tuj1) to visualize neurons. At E14.5 Cx3cr1-GFP ${ }^{+}$macrophages could be detected throughout the whole tongue tissue with no specific localization pattern (Fig. 5c). This continued through postnatal day $\mathrm{p} 0$ and until p10, whereby $C \times 3 c r 1-\mathrm{GFP}^{+}$macrophages were still dispersed throughout the tongue but started to align along the lamina propria. At these stages, taste bud maturation is observed ${ }^{26,27}$ and we detected the first $C \times 3 c r 1-G_{F P}{ }^{+}$ macrophages in proximity to fungiform papillae (Fig. 5c).

These data demonstrate the progression of a dynamic tongue macrophage compartment during mouse tongue development and that the specific localization of tongue macrophages in distinct anatomical niches is only established during postnatal stages.

\section{Molecular characterization of tongue macrophages during development}

The histological analysis reveals the unordered distribution of $C \times 3 c r 1-G F P^{+}$macrophages during early developmental stages towards distinct localization at adulthood. However, it is not clear from our histological data whether this reflects a sequential developmental maturation of macrophages or rather a progressive exchange of embryonic populations with adult, bone marrow-derived monocytes.

To gain further insight into this question, we investigated the tongue immune compartment from mice at post-natal day 3 (p3) with scRNA-seq. We chose p3 since it is the stage at which we could first identify $C \times 3 c r 1-G F{ }^{\text {int }}$ FOLR2 ${ }^{+}$macrophages by flow cytometry (Fig. 5b). We sequenced 13898 cells (from a pool of $n=7$ mice) and overlaid the data on the scRNA-seq data derived from adult mice (Fig. 6a). All adult tongue immune cell populations were also present at $p 3$, however, we noticed major differences in the frequency of several populations. Notably, p3 tongues harbored more mast cells (clusters 11 \& 13) and fewer Fn1+ myeloid cells (cluster 6) than adult tongues (Fig. 6b). We also detected a newly appearing cluster of cells in p3 tongues (cluster 2), which was almost absent in adult mice (Fig. 6b). These cluster 2 cells expressed high levels of proliferation-related genes, including Top2a, Ccnb2, Mki67, and further showed expression of typical macrophage lineage genes such as Cx3cr1, TIr4, Pf4 and Lyve1, which suggests they represent proliferating macrophage precursor cells (Fig. 6c). Indeed, when the UMAP is projected in 3D, cluster 2 cells seemed to incorporate into tFOLR2-MF (Fig. 6d; Suppl. Data 8). To investigate the connection of cluster 2 precursors with tongue macrophages we used Slingshot, which models developmental trajectories in scRNA-seq data ${ }^{28}$. Slingshot analysis revealed a possible bifurcation of the precursor cells at the cluster 1 level at which trajectories either 
split into cluster 0 or cluster 5 cells (Fig. 6e), which might indicate that both tFOLR2-MF and tCX3CR1-MF populations derive from a common precursor.

We confirmed the proliferation activity of macrophage precursor cells at p3 by EdU in vivo labelling. One day after injection, EdU incorporation could be readily observed in about $30-40 \%$ of $\mathrm{CD} 68^{+} \mathrm{FOLR}{ }^{+}$cells, while both adult tongue macrophage subsets showed no signs of homeostatic proliferation (Fig. 6f).

We then investigated whether peripheral cells like monocytes could adapt to the tongue macrophage niches in an immune compromised condition, e.g. after whole body irradiation. We performed bone marrow (BM) chimeric experiments, in which CD45.1 BM cells were transferred into irradiated CD45.2 recipients. We analyzed the composition of donor versus host tongue macrophages 5 and 10 weeks after transfer. While tCX3CR1-MF were already replaced by monocyte-derived cells 5 weeks after transfer, the tFOLR2-MF still comprised 53\% (+/- 6 SD) donor cells and accordingly, showed a slower replacement (Fig. $\mathbf{6 g}$ ). At 10 weeks after irradiation, both tongue macrophage subsets were exclusively of hematopoietic stem cell (HSC) origin. These data indicate that both tongue macrophage niches can be repopulated by myeloid precursors during adulthood.

To further explore the monocyte-dependency of tCX3CR1-MF and tFOLR2-MF under homeostatic conditions, we profiled the tongue-resident immune compartment of Irf8deficient mice, which lack $L y 6 C^{+}$monocytes and show reduced numbers of $L y 6 C^{-}$monocytes ${ }^{18,29}$. In total, $9047 \mathrm{CD} 45^{+}$cells were profiled from adult Irf8-deficient mice (pool of $\mathrm{n}=5$ mice) by scRNA-seq (Suppl. Fig. 5). All tongue-resident hematopoietic cell populations that were present in WT animals could also be identified in Irff-/- mice including dendritic cells, tCX3CR1-MF and tFOLR2-MF. In addition to the unchanged mononuclear phagocyte subset composition in $/ r 8^{-/-}$mice, the transcriptome of tCX3CR1-MF and tFOLR2-MF was also largely unaffected by the absence of the transcription factor IRF8 (9 DEGs for $C \times 3 c r 1^{+}$and 9 DEGs for Folr2 ${ }^{+}$macrophages; Suppl. Fig. 5).

Taken together, these experiments indicated that macrophage precursor cells proliferate locally and give rise to both tongue macrophage subsets. However, during adulthood and under immune compromised conditions, tCX3CR1-MF and tFOLR2-MF can be replaced by HSC-derived cells. 


\section{Discussion}

Despite the significance of the tongue as a site of interaction between microbes and the host, its cellular immune composition is not well investigated, especially not on the transcriptomic level. In light of the emerging role of different immune cells such as ILCs, regulatory $\mathrm{T}$ cells or macrophages in tissue remodeling, nerve surveillance and homeostatic tissue organization ${ }^{18,20,30,31}$, we characterized the mouse tongue-resident immune cell compartment under physiological conditions. We confirmed the existence of tLCs, cDCs and ${\text { Ly } 6 C^{+} \text {monocytes in the tongue }}^{9,32,33}$ and additionally identified two new subsets of tongueresident macrophages, one of which was characterized by Folr2 and Lyve1 expression, while the other subset expressed high levels of Cx3cr1, MHCll-related genes and Itgax (encoding CD11c). The phenotype of these two tongue macrophage populations is reminiscent of the two recently defined interstitial macrophage populations which are present across various organs ${ }^{19,22}$. In agreement with this, our bulk RNA-seq analysis revealed greater transcriptional similarities of tongue macrophages with interstitial heart macrophages, for example, than with TRMs such as Langerhans cells or microglia.

Chakarov et al., further described an association of Lyve $1^{+}$macrophages with blood vessels and $\mathrm{C} \times 3 \mathrm{Cr}^{+}{ }^{+}$macrophages with nerve fibers ${ }^{19}$. In the adult tongue, tFOLR2-MF were distributed across both the lamina propria and the deep muscle of the tongue, but were absent from the epithelium. We could also observe the association of tFOLR2-MF to CD31 ${ }^{+}$ blood vessels. On the other hand, tCX3CR1-MF are largely restricted to the highly innervated lamina propria and along the fibers of the chorda tympani branch of the facial nerve. In addition, rare clusters of $\mathrm{C} \times 3 \mathrm{Cr}^{+}$macrophages could also be detected in innervated posterioir areas of the tongue. It is therefore quite likely that the previously characterized CD11C "dendritic cells" in the lamina propria of the human and mouse tongues 7,34 correspond to the cells described here as tCX3CR1-MF.

The proximity of tCX3CR1-MF to nerves raises the question of whether they perform specific nerve-associated functions. In the skin, large, peripheral nerve-associated $C \times 3 c r 1^{+}$ macrophages were recently described ${ }^{18}$ that were involved in the maintenance of myelin sheath integrity and axon sprouting after injury and had a transcriptional signature related to nervous system functions. This particular signature was absent from tCX3CR1-MF, although tCX3CR1-MF did express some genes that are enriched in microglia (e.g. Hexb, Apoe) that also reside in close proximity to neurons. Various cranial nerve ganglia innervate the tongue tissue during embryogenesis and axons are guided by multiple chemoattractive factors to the tongue epithelium such as brain derived neurotrophic factor (BDNF) ${ }^{35}$. It is known that microglia-derived BDNF plays an important role in synapse formation and plasticity in the adult brain ${ }^{36}$. It is therefore possible that the subsequent postnatal maturation of taste 
receptor cells and the synaptic interconnectivity with neurons might be influenced by tCX3CR1-MF. The interesting topic of whether and how macrophages interact with nerves in the tongue needs further investigation.

It is also possible that tongue macrophages contribute directly or indirectly to instances of taste dysfunction. Various infections including Covid-19 or middle ear infections ${ }^{37-39}$, different medical treatment regimens ${ }^{40}$ and aging ${ }^{41}$ have all been associated with taste disruption. Taste bud maintenance relies on a continuous renewal of differentiated taste receptor cells ${ }^{42}$ and it has been shown that systemic inflammation like peripheral LPS injection increases TNF $\alpha$ and IL10 production by taste cells ${ }^{43,44}$, inhibits taste progenitor cell proliferation and interferes with taste cell renewal ${ }^{45}$. Such a mechanism might explain taste disorders associated with infections in general. We showed that systemic inflammation also causes a direct response from tongue-resident macrophages. We did not investigate the precise contribution of inflammation to taste sensation, yet consider the possibility that tongue macrophages may release cytokines and potentially neurotoxic products that could cause nerve damage. The reverse has also been shown, that tissue macrophages can also mediate neuronal protection and therefore limit neuronal damage upon infection ${ }^{46}$. Whether and how the various tongue mononuclear phagocytes are involved in taste perception remains to be explored and could be of clinical relevance in conditions such as anorexia or cancer, where appetite- and weight-loss is often aggravated by taste-dysfunctions.

The question remains of the role of tongue immunity in cases where tongue homeostasis is disrupted. It was recently shown that tongue $\mathrm{CD} 163^{+}$macrophages infiltrate tumor tissue in squamous cell carcinoma at a high frequency ${ }^{5}$. CD $163^{+}$macrophages were interpreted to be "M2 macrophages", and increased infiltration correlated with worse outcomes compared to patients with a high infiltration of $\mathrm{CD}_{11 \mathrm{C}^{+}}$"M1" macrophages 5 . Regardless of whether the "M1/M2" classification really applies to in vivo situations ${ }^{47}$, our data corroborate the notion of the existence of distinct subsets of tongue macrophages, which might respond differently to tumor-specific environmental cues.

We present a comprehensive catalog of immune cells in the murine tongue in physiological conditions and upon LPS-induced systemic inflammation. We identified two novel macrophage subsets in the tongue, namely tCX3CR1-MF and tFOLR2-MF, and place these findings in the context of mammalian macrophage biology. We hope that these data will encourage and support further investigations of the tongue as barrier and as an underrated immunological organ. 


\section{Methods}

\section{Ethics statement, experimental reporting \& study design}

This study was performed in strict accordance with national and international guidelines for the care and use of laboratory animals (Tierschutzgesetz der Bundesrepublik Deutschland, European directive 2010/63/EU, as well as GV-SOLAS and FELASA guidelines and recommendations for laboratory animal welfare). The animal experiment permission was obtained from the Landesamt für Gesundheit und Soziales (LAGeSo, Berlin). Most of the mice that were used in this study were also part of other experiments, in order to reduce animal experiments and suffering.

\section{Mice}

We used the following mouse strains: C57BL/6N wildytpe mice, B6(Cg)-Irf8tm1.2Hm/J (Irf8 ${ }^{-/}$; Jackson laboratory, stock number: 018298), B6.SJL-Ptprca Pepcb/BoyJ (CD45.1/1; Jackson laboratory, stock number: 002014) and B6.129P2(Cg)-Cx3cr1tm1Litt/J (Cx3cr1 $\left.{ }^{\mathrm{Gfp}}{ }^{21}\right)$. For BM chimeras, 8-12 weeks old recipient animals (CD45.2/2) were lethally irradiated (950 rad) and reconstituted with $10^{6} \mathrm{BM}$ cells isolated from WT (CD45.1/1) BM cells. The animals received Ciproxin in their drinking water for 10 days after irradiation. BM chimeras were analyzed 5 and 10 weeks after transfer. Mice were bred and housed at specific pathogenfree (SPF) animal facilities of the Max-Delbrück-Center for Molecular Medicine in Berlin, Germany or at the Weizmann Institute of Science in Rehovot, Israel. Mice were kept in standard conditions $\left(22 \pm 1^{\circ} \mathrm{C}\right)$ under a 12-hour light cycle with experiments carried out during the "lights-on" phase. Mice had access to a chow diet ad libitum and cages were lined with chip bedding and enriched with a mouse tunnel/igloo.

\section{Cell suspensions for fluorescence-activated cell sorting}

Adult mice were anesthetized by intraperitoneal injection of $150 \mathrm{mg} / \mathrm{kg}$ body weight pentobarbital sodium (WDT) and intracardially perfused with PBS.

Brain: Brains were dissected, and the olfactory bulb and cerebellum were removed. The remaining brain was minced and filtered through a $70 \mu \mathrm{m}$ cell strainer in ice-cold highglucose DMEM (Sigma). The cell suspension was centrifuged at $1,200 \mathrm{rpm}$ at $4^{\circ} \mathrm{C}$ for 6 minutes and the pellet was resuspended in $5 \mathrm{ml}$ of $40 \%$ Percoll (GE Healthcare) in PBS and transferred to a $15 \mathrm{ml}$ tube. Tubes were centrifuged at 2,000 rpm for 25 minutes ( $\mathrm{min}$ ) at $14^{\circ} \mathrm{C}$ with no acceleration nor break. Pellet was resuspended in $10 \mathrm{ml}$ sorting buffer and centrifuged for $6 \mathrm{~min}$ at 1,200 rpm and $4^{\circ} \mathrm{C}$. Leukocyte-containing cell pellets were further processed. 
Colon: Cells from $\mathrm{C} \times 3 \mathrm{cr} 1^{\mathrm{Gfp} / \mathrm{t}}$ mice were isolated as previously described ${ }^{48}$. In brief, the intestine was removed and feces were flushed with cold PBS without calcium and magnesium. The intestine was longitudinally opened and cut into $0,5 \mathrm{~cm}$ pieces. Intestinal epithelial cells were removed by incubation with the HBSS containing $1 \mathrm{mM}$ DTT, $2 \mathrm{mM}$ EDTA and $5 \%$ of fetal calf serum. The cell suspension was incubated at $37^{\circ} \mathrm{C}, 125 \mathrm{rpm}$ for $40 \mathrm{~min}$. The cell suspension was shortly vortexed and passed through a $100 \mu \mathrm{m}$ mesh. The intestinal tissue pieces were transferred to a $50 \mathrm{ml}$ Falcon tube containing $5 \mathrm{ml}$ PBS with $5 \%$ FBS, $1 \mathrm{mg} / \mathrm{ml}$ of collagenase VIII (Sigma) and $0.1 \mathrm{mg} / \mathrm{ml}$ DNase I. Samples were incubated at $37^{\circ} \mathrm{C}, 250 \mathrm{rpm}$ for $40 \mathrm{~min}$. Digested colon tissue was vortexed for $40 \mathrm{sec}$, passed through a $80 \mu \mathrm{m}$ mesh and cells were collected by centrifugation at $1,200 \mathrm{rpm}$ for $10 \mathrm{~min}$ at $4{ }^{\circ} \mathrm{C}$. Cells were stained after CD16/32 block with antibodies against CD45, CD11b, lineage (Ly6C, Ly6G, B220) and MHCII.

Heart: The heart of $\mathrm{Cx} 3 \mathrm{cr} 1^{\mathrm{Gfp} /+}$ mouse was removed, the organ was chopped into small pieces and digested for $30 \mathrm{~min}$ at $37^{\circ} \mathrm{C}$ in RPMI medium without fetal calf serum supplemented with $1 \mathrm{mg} / \mathrm{ml}$ Collagenase IV and $1 \mathrm{mg} / \mathrm{ml}$ DNase I. The digestion was stopped by addition of staining buffer (2mM EDTA, 1\% FCS in PBS) and the cell suspension was minced through a $100 \mu \mathrm{m}$ cell strainer. After centrifugation at $1,200 \mathrm{rpm}, 4^{\circ} \mathrm{C}$ for $6 \mathrm{~min}$, supernatant was discarded and cells were blocked with anti-CD16/32 antibodies for $10 \mathrm{~min}$, before anti-F4/80-biotin antibodies were added for $25 \mathrm{~min}$ on ice. After washing, the cell pellet was incubated with anti-biotin beads (Miltenyi) for $15 \mathrm{~min}$ on ice. Cells were washed again (1,200 rpm, $4^{\circ} \mathrm{C}$ for $6 \mathrm{~min}$ ) and MACS was performed with LS columns (Miltenyi). After elution and washing of cells, lung cells were stained for CD45, streptavidin, dump (Ly6C, Ly6G), CD11b, MerTK, CD64 and MHCII

Lung: The lung was removed and cut into small pieces. Tissue was collected in RPMI medium without fetal calf serum supplemented with $1 \mathrm{mg} / \mathrm{ml}$ Collagenase $A$ and $1 \mathrm{mg} / \mathrm{ml}$ DNase I. Tissue was digested for $30 \mathrm{~min}$ at $37^{\circ} \mathrm{C}$. The suspension was minced and filtered through a $100 \mu \mathrm{m}$ cell strainer. The cell suspension was centrifuged at $1,200 \mathrm{rpm}, 4^{\circ} \mathrm{C}$ for 6 min. The supernatant was removed and cells were blocked with anti-CD16/32 antibodies for $10 \mathrm{~min}$, before anti-CD45-biotin antibodies were added for $25 \mathrm{~min}$ on ice. Afterwards, cells were washed with staining buffer (2mM EDTA, 1\% FCS in PBS) at 1,200 rpm, $4^{\circ} \mathrm{C}$ for $6 \mathrm{~min}$, supernatant was discarded and anti-biotin beads (Miltenyi) were added for $15 \mathrm{~min}$. Cells were washed again $\left(1,200 \mathrm{rpm}, 4^{\circ} \mathrm{C}\right.$ for $\left.6 \mathrm{~min}\right)$ and MACS was performed with LS columns (Miltenyi). After elution and washing of cells, lung cells were stained for lineage (Ly6C, Ly6G), streptavidin, CD11b, CD64, CD11c and SiglecF.

Spleen: The spleens were removed from BI6 mice and minced through a $100 \mu \mathrm{m}$ cell strainer. After washing with staining buffer (2mM EDTA, 1\% FCS in PBS) at 1,200 rpm, $4^{\circ} \mathrm{C}$ for 6 min, supernatant was discarded and cells were blocked with anti-CD16/32 antibodies 
for $10 \mathrm{~min}$, before anti-F4/80-biotin antibodies were added for $25 \mathrm{~min}$ on ice. After washing, the cell pellet was incubated with anti-biotin beads (Miltenyi) for $15 \mathrm{~min}$ on ice. Cells were washed again $\left(1,200 \mathrm{rpm}, 4^{\circ} \mathrm{C}\right.$ for $\left.6 \mathrm{~min}\right)$ and MACS was performed with LS columns (Miltenyi). After elution and washing of cells, lung cells were stained for CD45, streptavidin, lineage (Ly6C, Ly6G, B220), CD11b, CD11c and MHCII.

Skin Langerhans cells: Ears were dissected and placed over 0.05\% Trypsin with EDTA in PBS for $1.5-2$ hours at $37^{\circ} \mathrm{C}$, until the epidermis could be peeled off using forceps. The epidermis was minced and the crude tissue suspension in sorting buffer was passed through a $100 \mu \mathrm{m}$ cell strainer and centrifuged for $6 \mathrm{~min}$ at $1,200 \mathrm{rpm}$ and $4^{\circ} \mathrm{C}$. Cell-pellets were further processed.

Tongue leukocytes: Tongues were extracted, minced in $500 \mu \mathrm{L}$ of PBS with $0.2 \mathrm{mg}$ of DNAse I (Roche), $2.4 \mathrm{mg}$ Collagenase IV (Gibco) and $0.15 \mathrm{mg}$ (60U) hyaluronidase I (Sigma) and incubated for $45 \mathrm{~min}$ at $37^{\circ} \mathrm{C}$. $10 \mathrm{ml}$ sorting buffer were added to the crude tissue suspension as it was passed through a $100 \mu \mathrm{m}$ cell strainer and centrifuged for 6 min at $1,200 \mathrm{rpm}$ and $14^{\circ} \mathrm{C}$. Pellet was resuspended in $3 \mathrm{ml} \mathrm{PBS}$, layered over $3 \mathrm{ml}$ of FicollPaque $^{\mathrm{TM}}$ and centrifuged for $17 \mathrm{~min}$ at $2,000 \mathrm{rpm}$ and $14^{\circ} \mathrm{C}$ with no acceleration nor break. The interface containing leukocytes was collected, $5 \mathrm{ml}$ sorting buffer were added centrifuged for $6 \mathrm{~min}$ at $1,200 \mathrm{rpm}$ and $4^{\circ} \mathrm{C}$. Leukocyte-containing cell pellets were further processed. All tongue preparations were performed according to this protocol, if not otherwise stated.

Tongue Langerhans cells: To separate the epithelium from the rest of the tongue and to dislodge Langerhans cells, extracted tongues were injected with $5 \mathrm{U} / \mathrm{ml}$ of Dispase II (Sigma) in HEPES buffered saline until completely distended. They were then incubated for $15 \mathrm{~min}$ at $37^{\circ} \mathrm{C}$ and the epithelium layer was peeled off using forceps. The epithelium was minced in $500 \mu \mathrm{L}$ of PBS with $0.2 \mathrm{mg}$ of DNAse I (Roche), $4.8 \mathrm{mg}$ Collagenase IV (Gibco) and $0.15 \mathrm{mg} \mathrm{(60U)} \mathrm{hyaluronidase} \mathrm{I} \mathrm{(Sigma)} \mathrm{and} \mathrm{incubated} \mathrm{for} 15 \mathrm{~min}$ at $37^{\circ} \mathrm{C} .10 \mathrm{ml}$ sorting buffer were added to the crude tissue suspension as it was passed through a $100 \mu \mathrm{m}$ cell strainer and centrifuged for $6 \mathrm{~min}$ at $1,200 \mathrm{rpm}$ and $4^{\circ} \mathrm{C}$. The pellet (enriched for tongue Langerhans cells) was then further processed accordingly.

\section{Flow cytometry and cell sorting}

Cell suspensions were kept on ice. They were blocked with anti-CD16/32 (2.4G2) antibodies for $10 \mathrm{~min}$ and then stained for 20-25 min with antibodies against mouse CD45 (30-F11), CD45.2 (104), CD45.1 (A20), CD11b (M1/70), CD11c (N418), CD64 (X54-5/7.1), CX3CR1 (SA011F11), F4/80 (BM8), Folr2 (10/FR2), EpCam (G8.8), Gr1 (RB6-8C5), IA/IE (M5/114.15.2), B220 (Ra3-6B2), Ly6C (HK1.4), Ly6G (1A8), Lyve1 (ALY7), MerTK (2B10C42), Siglec-F (E50-2440) and TIMD4 (RMT4-54). Antibodies were purchased from 
BioLegend or eBioscience. The gating strategy for all macrophage populations is presented in Suppl. Fig. 3. Samples were washed in $2 \mathrm{ml}$ sorting buffer and centrifuged for $6 \mathrm{~min}$ at $1,200 \mathrm{rpm}$ and $4^{\circ} \mathrm{C}$. Pellet was resuspended in sorting buffer and flow sorted using Arial, Ariall or Arialll (BD Biosciences, BD Diva Software) cell sorters. Flow cytometry analysis was performed on Fortessa or LSRII (BD Biosciences, BD Diva Software) and analyzed with FlowJo software v.10.7.1 (BD).

\section{scRNAseq}

Experiment 1 (Fig. 1): Tongues were prepared as described in the material \& method section. 8 adult, female BI6 mice were used for the isolation of interstitial cells with collagenase / hyaluronidase digestion. 4 adult, female BI6 mice were used to isolate tongue Langerhans cells with dispase digestion. Both preparations were pooled and CD $45^{+}$cells were analyzed with Chromium ${ }^{\mathrm{TM}}$ Single Cell 3' Reagent Kits v3.1.

Experiment 2 (Suppl. Fig. 1a): scRNA-seq was performed on $\mathrm{CD} 45^{+}$tongue hematopoietic cells isolated from $10 \mathrm{Bl} 6$ mice. Tongues were extracted, minced in $500 \mu \mathrm{L}$ of PBS and digested with $0.2 \mathrm{mg}$ of DNAse I (Roche) and $1 \mathrm{mg}$ Collagenase IV (Gibco). $10 \mathrm{ml}$ sorting buffer were added and tissue suspension was passed through a $100 \mu \mathrm{m}$ cell strainer and centrifuged for $6 \mathrm{~min}$ at $1,200 \mathrm{rpm}$ and $14^{\circ} \mathrm{C}$. Cells in the pellet were stained for anti-CD45. FACS-purified CD $45^{+}$cells were used for scRNA-seq. scRNA-seq was performed with the Chromium $^{\mathrm{TM}}$ Single Cell 3' Reagent Kits v2.

Experiment 3 (Fig. 4): Cell isolation of LPS-injected female Bl6 mice was performed as mentioned above. 6 mice were used for interstitial cell isolation and 4 mice for Langerhans cell extraction. Both samples were pooled and $\mathrm{CD}^{+} 5^{+} \mathrm{DAPl}{ }^{-}$cells were analyzed with Chromium ${ }^{\mathrm{TM}}$ Single Cell 3' Reagent Kits v3.1.

Experiment 4 (Fig. 5): Cell isolation of p3-p4 BI6 mice was performed as mentioned above. 7 mice were used for interstitial cell isolation. $\mathrm{CD} 45^{+} \mathrm{DAPl}{ }^{-}$cells were analyzed with Chromium ${ }^{\mathrm{TM}}$ Single Cell 3' Reagent Kits v3.1.

Experiment 5 (Suppl. Fig. 5): Cell isolation of Irf8 ${ }^{-/-}$female Bl6 mice was performed as mentioned above. 5 mice were used for interstitial cell isolation. No additional Langerhans cell extraction was performed for this experiment. CD45 ${ }^{+} \mathrm{DAPl}$ cells were analyzed with Chromium $^{\mathrm{TM}}$ Single Cell 3' Reagent Kits v3.1.

\section{RNA isolation and cDNA synthesis for bulk RNA-Seq}

500-20,000 sorted cells were lysed with $100 \mu$ of lysis/binding buffer (Life Technologies), snap-frozen on dry ice and stored at $-80^{\circ} \mathrm{C}$ until further use. mRNA purification was performed with the Dynabeads ${ }^{\mathrm{TM}}$ mRNA DIRECT ${ }^{\mathrm{TM}}$ Purification Kit (Life Technologies) according to the manufacturer's guidelines. MARS-seq barcoded RT primers were used for 
reverse transcription with the Affinity Script cDNA Synthesis Kit (Agilent) in a $10 \mu$ reaction volume.

\section{Bulk RNA-sequencing}

The MARS-seq protocol was used for bulk RNA sequencing ${ }^{49}$. After reverse transcription, samples were analyzed by $\mathrm{qPCR}$ and samples with similar $\mathrm{Ct}$ values were pooled. Samples were treated with Exonuclease I (New England BioLabs (NEB)) for $30 \mathrm{~min}$ at $37^{\circ} \mathrm{C}$ and for 10 min at $80^{\circ} \mathrm{C}$ followed by a $1.2 \mathrm{X}$ AMPure XP beads (Beckman Coulter) cleanup. The second strand synthesis kit (NEB) at $16^{\circ} \mathrm{C}$ for 2 hours was used for cDNA synthesis followed by a 1.4X AMPure XP bead cleanup. In vitro transcription (IVT) was performed at $37^{\circ} \mathrm{C}$ for $13-16 \mathrm{~h}$ with the HiScribe T7 RNA Polymerase kit (NEB). The remaining DNA was digested by Turbo DNase I (Life Technologies) treatment at $37^{\circ} \mathrm{C}$ for $15 \mathrm{~min}$ followed by a $1.2 \mathrm{X}$ AMPure XP bead cleanup. RNA fragmentation (Invitrogen) was performed at $70^{\circ} \mathrm{C}$ and the reaction was stopped after 3min with Stop buffer (Invitrogen) followed by a 2X AMPure XP bead cleanup. Ligation of the fragmented RNA to the MARS-seq adapter was performed at $22^{\circ} \mathrm{C}$ for $2 \mathrm{~h}$ with T4 RNA ligase (NEB) followed by a 1.5X AMPure XP bead cleanup. A second reverse transcription reaction was performed with MARS-seq RT2 primer and the Affinity Script cDNA Synthesis Kit (Agilent Technologies) followed by $1.5 \mathrm{X}$ AMPure XP bead cleanup. Finally, the library was amplified using P5_Rd1 and P7_Rd2 primers and the Kapa HiFi Hotstart ready mix (Kapa Biosystems) followed by a 0.7X AMPure XP bead cleanup. Fragment size was measured using a TapeStation (Agilent Technologies) and library concentrations were measured with a Qubit fluorometer (Life Technologies). The samples were sequenced using a NextSeq 500 system (Illumina).

\section{Microscopy}

Tissue preparation: Mice were deeply anesthetized with a combination of $150 \mathrm{mg} / \mathrm{kg}$ body weight pentobarbital sodium (WDT) and perfused transcardially for $3 \mathrm{~min}$ with ice-cold $0.9 \%$ $\mathrm{NaCl}$ solution and for 5 min with $4 \%$ paraformaldehyde (PFA) in $0.1 \mathrm{M}$ phosphate buffer (PB). Tongues were post-fixed overnight in $4 \%$ PFA in $0.1 \mathrm{M}$ PB. They were then cryoprotected by $3 \times$ overnight incubations in $30 \% \mathrm{w} / \mathrm{v}$ sucrose in $0.1 \mathrm{M} \mathrm{PB}$, cryosectioned with a cryostat (35 $\mu \mathrm{m}$ sagittal) and mounted directly to slides for staining.

Immunohistochemistry: $35 \mu \mathrm{m}$ sagittal tongue sections from the tongue midline were washed for $5 \mathrm{~min}$ at RT in TBS (42mM Tris $\mathrm{HCl}, 8 \mathrm{mM}$ Tris Base, $154 \mathrm{mM} \mathrm{NaCl}$; pH 7.4). Sections were blocked in $20 \%$ normal donkey serum (NDS) in TBS-T for 1 hour at RT and incubated overnight at $4^{\circ} \mathrm{C}$ in primary antibody diluted in TBS-T $+2 \%$ NDS/NGS. Primary antibodies against CD31 (Millipore MAB13982; 1:200), CD68 (Bioloegend 137002; 1:100), GFP 
(AbCam; ab13970; 1:200), Lyve-1 (ReliaTech 103-PA50AG; 1:500), Podoplanin (Biolegend 156202; 1:50), Tuj1 (AbCam ab18207; 1:200) were used. Sections were then washed $3 \times 30$ min in TBST and incubated overnight at $4^{\circ} \mathrm{C}$ with appropriate secondary antibodies raised in goat and conjugated to Alexa Fluor dyes (Invitrogen) were diluted 1:500 or 1:1000 in TBS-T $+2 \%$ NDS/NGS. Sections were washed $3 \times 30 \mathrm{~min}$ in TBST and nuclei were stained with DAPI at a $0.5 \mathrm{mg} / \mathrm{ml}$ in TBS. After washing, sections were mounted with FluorSave reagent (Calbiochem).

Imaging and quantification. Imaging was performed using a Leica SP5 TCE. Four regions (R1-R4; Fig. 3e) from three consecutive sagittal $35 \mu \mathrm{m}$ slices at the tongue midline were imaged at $775.76 \times 734.76 \mu \mathrm{m}$ dimensions and over a depth of $30 \mu \mathrm{m}$ with $1.5 \mu \mathrm{m}$ z-stack intervals. All image processing was done with $\mathrm{Fiji}^{50}$ and quantifications were performed with Imaris Microscopy Image Analysis Software (Bitplane). Regions of interest (ROI: muscle or lamina propria) were manually drawn onto each z-stack image and the software's built-in surface module extrapolated the volume of the respective ROI. Then, the built-in surface detection algorithm was used to identify cells $\left(\mathrm{LYVE} 1^{+}\right.$or $\left.C \times 3 c r 1-\mathrm{GFP}^{+}\right)$in each $\mathrm{ROI}$, so that we could calculate number of cells and mean cell volumes per ROI volume.

\section{Lipopolysaccharide induced systemic inflammation}

Mice were injected intraperitoneally with 1 mg/kg LPS (E. coli 0111:B4) in $200 \mu$ I PBS 6 hours prior to sacrifice.

\section{Cell proliferation assay (EdU)}

The EdU Click 488 Kit from BaseClick were used. In brief, $0.5 \mathrm{mg} / \mathrm{g}$ of EDU in PBS was injected intraperitoneally to adult mice or subcutaneously to pups 15 hours before to sacrifice. Single cell suspensions were obtained from tongues (see relevant section) and cells were processed according to the manufacturer's instructions.

\section{Sequencing Data Analysis}

Bulk sequencing data analysis. Using the fastq files, the reads were deduplicated based on their UMls. Subsequently, STAR (version 2.5.3a) was applied for the alignment of reads to the mouse genome (mm9). Quantification of reads by htseq-count (version 1.0) yielded the input expression matrix for DESeq2 (version 1.26.0), used to identify differentially expressed genes for each group. More specifically, each group was compared against all other groups to obtain DE marker genes.

Single cell sequencing data analysis. 
Preprocessing and integration. The data was sequenced with 10x Genomics (version v3.1) For alignment to $\mathrm{mm} 10$ and quantification Cell Ranger Single Cell Software was used. For additional preprocessing and downstream analysis Seurat (v4) was applied. First, based on the UMI counts, cells were filtered based on the number of detected genes and the proportion of mitochondrial gene counts. All cells with more than $10 \%$ mitochondrial gene count were removed. For the number of detected genes, a sample specific filtering value was applied, for experiment 2 (10x Chromium v2) the accepted range was between 300 and 2000, for the remaining samples a minimum of 500 was required while the maximum cutoff ranged from 5000 (experiment 1) over 5500 (experiment 3) to 6000 (experiment 4). The data was normalized and the 4000 most valiable genes were selected. Subsequently, the data was analyzed together by applying Seurats integration function (FindlntegrationAnchors) and making use of the pre-computed anchors (FindlntegrationAnchors), i.e. genes used to map the cells from different samples. Analogously, experiment 5 (Irf8-deficient cells) and experiment 1 were integrated. For the IRF8 sample, the range of detected genes for included cells was set to 500-5500 and cells with more than $10 \%$ mitochondrial gene count were removed.

Dimension Reduction, unsupervised clustering and marker detection. A principal component analysis provided the basis for the computation of a UMAP and an unsupervised clustering of the cells. The resolution parameter for FindClusters was set to $0.42(0.25$ for experiment 5). Conserved cluster markers for all samples were computed using FindConservedMarkers with the detection method set to 'MAST'. Genes differentially expressed between clusters of different samples were detected analogously using FindClusters.

Cell cluster annotation, trajectory inference and signature enrichment. To assign cell types to the clusters identified, we applied SingleR (version $1.6 .1 ;{ }^{14}$ ), using the ImmGen database as annotation resource. Slingshot (version 2.0.0; ${ }^{28}$ ) was applied for trajectory inference. To this end, we provided slingshot with the newborn-specific cluster as starting point. To shed more light on the macrophagic versus dendritic nature of the cells in the central clusters, we computed the enrichment of macrophage-specific as well as dendritic gene sets by use of GSVA (version $1.40 .1 ;{ }^{15}$ ).

\section{Data and code availability}

Data that were generated within this study have been deposited in Gene Expression Omnibus (GEO) with the accession code GSEXXXX.

\section{Acknowledgement}


We would like to thank Jermaine $\mathrm{Voß}$ for excellent technical support, as well as the MDC animal facility, especially Juliette Bergemann, the MDC FACS core unit and Dr. Hans-Peter Rahn in particular, and the MDC genomic core facility, especially Caroline Braeuning. We thank Dr. Anca Margineanu, Dr. Sandra Cristina Carneiro Raimundo and the Advanced Light Microscopy Technology Platform of the MDC for the general and technical support. We are also grateful to Dr. Christoph Klose for advice on lymphocyte subset identification. A.M is a Heisenberg fellow supported by the DFG (Ml1328).

\section{Author contribution}

E.M.L., L-K.W. and D.D. performed experiments and analysis. K.Z. performed bioinformatic analysis. C.F. and T.C. helped with scRNA-seq experiments. A-H.H, S.Y., S.J., W.S. and S.D. provided critical mouse strains, reagents and intellectual input. A.L. provided resources, editing and lab space. A.M. financed, designed and supervised the study. A.M. and E.M.L wrote the manuscript.

\section{Competing interests}

The authors declare no competing interests. 


\section{References}

1. Wu, J. Y. Tongue as a first-line immune organ? Protein Cell 12, 162-164 (2021).

2. Burkhardt, A. et al. Interepithelial cells of the oral mucosa in mice. An ultrastructural classification with reflections on the origin of the Langerhans cell. Virchows Arch A Pathol Anat Histol 384, 223-244 (1979).

3. Darling, M. R. et al. Geographic tongue: assessment of peripheral nerve status, Langerhans cell, and HLA-DR expression. Oral Surg Oral Med Oral Pathol Oral Radiol 124, 371-377.e1 (2017).

4. Cruchley, A. T., Williams, D. M., Farthing, P. M., Lesch, C. A. \& Squier, C. A. Regional variation in Langerhans cell distribution and density in normal human oral mucosa determined using monoclonal antibodies against CD1, HLADR, HLADQ and HLADP. J. Oral Pathol. Med. 18, 510-516 (1989).

5. Agarbati, S. et al. Prognostic Relevance of Macrophage Phenotypes in High-grade Oral Tongue Squamous Cell Carcinomas. Appl Immunohistochem Mol Morphol 29, 359-365 (2021).

6. Shigeoka, M., Koma, Y.-I., Nishio, M., Akashi, M. \& Yokozaki, H. Alteration of Macrophage Infiltrating Compartment: A Novel View on Oral Carcinogenesis. Pathobiology 1-11 (2021). doi:10.1159/000515922

7. Feng, P. et al. Immune cells of the human peripheral taste system: dominant dendritic cells and CD4 T cells. Brain Behav. Immun. 23, 760-766 (2009).

8. Merad, M., Sathe, P., Helft, J., Miller, J. \& Mortha, A. The dendritic cell lineage: ontogeny and function of dendritic cells and their subsets in the steady state and the inflamed setting. Annu. Rev. Immunol. 31, 563-604 (2013).

9. Sparber, F. et al. Langerin+ DCs regulate innate IL-17 production in the oral mucosa during Candida albicans-mediated infection. PLoS Pathog. 14, e1007069 (2018).

10. Saba, Y. et al. Early antitumor activity of oral Langerhans cells is compromised by a carcinogen. Proc. Natl. Acad. Sci. U.S.A. 119, (2022).

11. Gondak, R. O., Alves, D. B., Silva, L. F. F., Mauad, T. \& Vargas, P. A. Depletion of Langerhans cells in the tongue from patients with advanced-stage acquired immune deficiency syndrome: relation to opportunistic infections. Histopathology 60, 497-503 (2012).

12. Cavallin, M. A. \& McCluskey, L. P. Lipopolysaccharide-induced up-regulation of activated macrophages in the degenerating taste system. J. Neurosci. Res. 80, 75-84 (2005).

13. Agyeman, A. A., Chin, K. L., Landersdorfer, C. B., Liew, D. \& Ofori-Asenso, R. Smell and Taste Dysfunction in Patients With COVID-19: A Systematic Review and Metaanalysis. Mayo Clin Proc 95, 1621-1631 (2020).

14. Aran, D. et al. Reference-based analysis of lung single-cell sequencing reveals a transitional profibrotic macrophage. Nature Immunology 20, 163-172 (2019).

15. Hänzelmann, S., Castelo, R. \& Guinney, J. GSVA: gene set variation analysis for microarray and RNA-seq data. BMC Bioinformatics 14, 7-15 (2013).

16. Gautier, E. L. et al. Gene-expression profiles and transcriptional regulatory pathways that underlie the identity and diversity of mouse tissue macrophages. Nature Immunology 13, 1118-1128 (2012).

17. Schlitzer, A. et al. Identification of CDC1- and CDC2-committed DC progenitors reveals early lineage priming at the common DC progenitor stage in the bone marrow. Nature Immunology 16, 718-728 (2015).

18. Kolter, J. et al. A Subset of Skin Macrophages Contributes to the Surveillance and Regeneration of Local Nerves. Immunity 50, 1482-1497.e7 (2019).

19. Chakarov, S. et al. Two distinct interstitial macrophage populations coexist across tissues in specific subtissular niches. Science 363, eaau0964 (2019).

20. Wolf, Y. et al. Brown-adipose-tissue macrophages control tissue innervation and homeostatic energy expenditure. Nature Immunology 18, 665-674 (2017).

21. Jung, S. et al. Analysis of fractalkine receptor CX(3)CR1 function by targeted deletion 
and green fluorescent protein reporter gene insertion. Mol. Cell. Biol. 20, 4106-4114 (2000).

22. Dick, S. A. et al. Three tissue resident macrophage subsets coexist across organs with conserved origins and life cycles. Sci Immunol 7, eabf7777 (2022).

23. Summers, K. M., Bush, S. J. \& Hume, D. A. Network analysis of transcriptomic diversity amongst resident tissue macrophages and dendritic cells in the mouse mononuclear phagocyte system. PLoS Biol 18, e3000859 (2020).

24. Lavin, $Y$. et al. Tissue-resident macrophage enhancer landscapes are shaped by the local microenvironment. Cell 159, 1312-1326 (2014).

25. Prevo, R., Banerji, S., Ferguson, D. J., Clasper, S. \& Jackson, D. G. Mouse LYVE-1 is an endocytic receptor for hyaluronan in lymphatic endothelium. J. Biol. Chem. 276, 19420-19430 (2001).

26. El-Sharaby, A., Ueda, K., Kurisu, K. \& Wakisaka, S. Development and maturation of taste buds of the palatal epithelium of the rat: histological and immunohistochemical study. Anat. Rec. 263, 260-268 (2001).

27. Harada, S., Yamaguchi, K., Kanemaru, N. \& Kasahara, Y. Maturation of taste buds on the soft palate of the postnatal rat. Physiol. Behav. 68, 333-339 (2000).

28. Street, $K$. et al. Slingshot: cell lineage and pseudotime inference for single-cell transcriptomics. BMC Genomics 19, 477-16 (2018).

29. Kurotaki, D. et al. Essential role of the IRF8-KLF4 transcription factor cascade in murine monocyte differentiation. Blood 121, 1839-1849 (2013).

30. Wang, K. et al. Neuronal, stromal, and T-regulatory cell crosstalk in murine skeletal muscle. Proc. Natl. Acad. Sci. U.S.A. 117, 5402-5408 (2020).

31. Monticelli, L. A. et al. Innate lymphoid cells promote lung-tissue homeostasis after infection with influenza virus. Nature Immunology 12, 1045-1054 (2011).

32. Park, J.-Y., Chung, H., Choi, Y. \& Park, J.-H. Phenotype and Tissue Residency of Lymphocytes in the Murine Oral Mucosa. Front Immunol 8, 250 (2017).

33. Tanaka, Y. et al. Oral CD103-CD11b+ classical dendritic cells present sublingual antigen and induce Foxp3+ regulatory $\mathrm{T}$ cells in draining lymph nodes. Mucosal Immunol 10, 79-90 (2017).

34. Mascarell, L. et al. Mapping of the lingual immune system reveals the presence of both regulatory and effector CD4+ T cells. Clin Exp Allergy 39, 1910-1919 (2009).

35. Ma, L., Lopez, G. F. \& Krimm, R. F. Epithelial-derived brain-derived neurotrophic factor is required for gustatory neuron targeting during a critical developmental period. J. Neurosci. 29, 3354-3364 (2009).

36. Parkhurst, C. N. et al. Microglia Promote Learning-Dependent Synapse Formation through Brain-Derived Neurotrophic Factor. Cell 155, 1596-1609 (2013).

37. Mahmoud, M. M. et al. Pathogenesis of dysgeusia in COVID-19 patients: a scoping review. Eur Rev Med Pharmacol Sci 25, 1114-1134 (2021).

38. Gautier, J.-F. \& Ravussin, Y. A New Symptom of COVID-19: Loss of Taste and Smell. Obesity (Silver Spring) 28, 848-848 (2020).

39. Michael, P. \& Raut, V. Chorda tympani injury: operative findings and postoperative symptoms. Otolaryngol Head Neck Surg 136, 978-981 (2007).

40. Wickham, R. S. et al. Taste changes experienced by patients receiving chemotherapy. Oncol Nurs Forum 26, 697-706 (1999).

41. Ogawa, T., Annear, M. J., Ikebe, K. \& Maeda, Y. Taste-related sensations in old age. J Oral Rehabil 44, 626-635 (2017).

42. Roper, S. D. \& Chaudhari, N. Taste buds: cells, signals and synapses. Nat. Rev. Neurosci. 18, 485-497 (2017).

43. Feng, P., Zhao, H., Chai, J., Huang, L. \& Wang, H. Expression and secretion of TNF- $\alpha$ in mouse taste buds: a novel function of a specific subset of type II taste cells. PLoS ONE 7, e43140 (2012).

44. Feng, P. et al. Interleukin-10 is produced by a specific subset of taste receptor cells and critical for maintaining structural integrity of mouse taste buds. J. Neurosci. 34, 2689-2701 (2014).

45. Cohn, Z. J., Kim, A., Huang, L., Brand, J. \& Wang, H. Lipopolysaccharide-induced 
inflammation attenuates taste progenitor cell proliferation and shortens the life span of taste bud cells. BMC Neurosci 11, 72-16 (2010).

46. Matheis, F. et al. Adrenergic Signaling in Muscularis Macrophages Limits InfectionInduced Neuronal Loss. Cell 180, 64-78.e16 (2020).

47. Nahrendorf, M. \& Swirski, F. K. Abandoning M1/M2 for a Network Model of Macrophage Function. Circ Res 119, 414-417 (2016).

48. Aychek, T. et al. IL-23-mediated mononuclear phagocyte crosstalk protects mice from Citrobacter rodentium-induced colon immunopathology. Nat Commun 6, 6525-10 (2015).

49. Jaitin, D. A. et al. Massively Parallel Single-Cell RNA-Seq for Marker-Free Decomposition of Tissues into Cell Types. Science 343, 776-779 (2014).

50. Schindelin, J. et al. Fiji: an open-source platform for biological-image analysis. Nat. Methods 9, 676-682 (2012). 
bioRxiv preprint doi: https://doi.org/10.1101/2022.02.09.479699; this version posted February 11, 2022. The copyright holder for this preprint (which was not certified by peer review) is the author/funder, who has granted bioRxiv a license to display the preprint in perpetuity. It is made available under aC $\mathscr{G}_{-}-\mathrm{BY} 4.0$ International license.

non-mononuclear phagocytes:
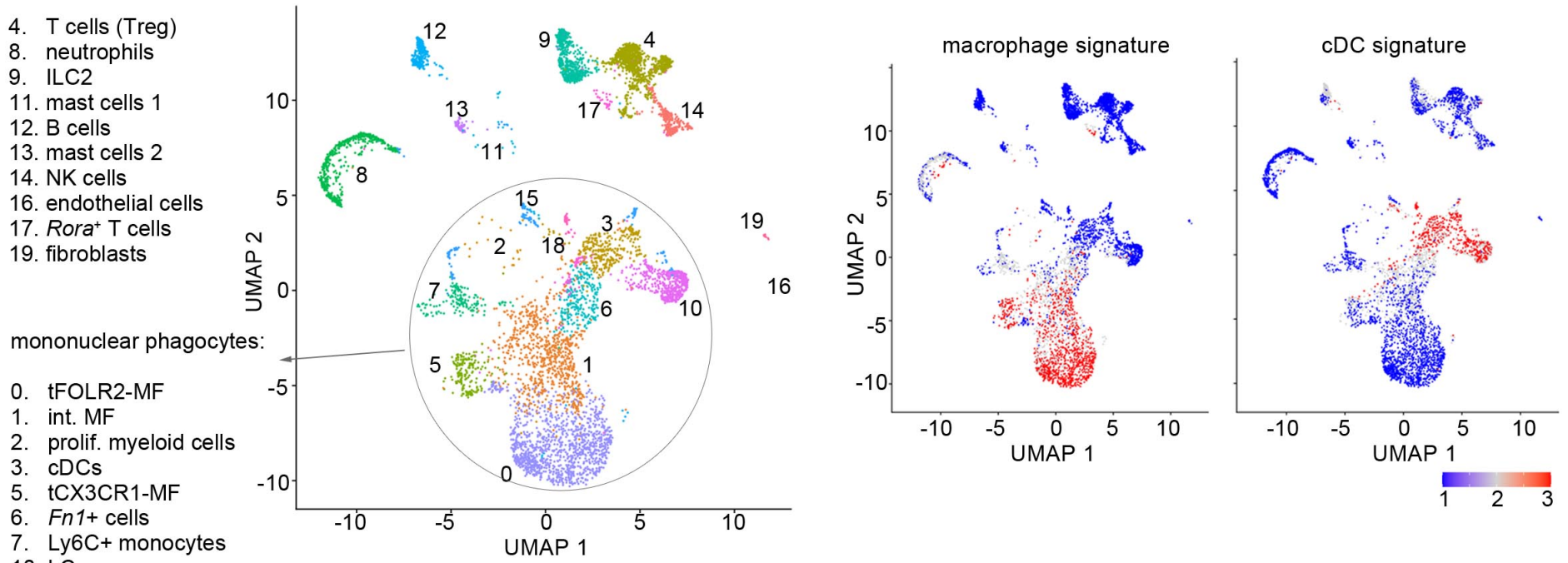

10. LC

15. preDC

18. cDCs

c

cluster 0
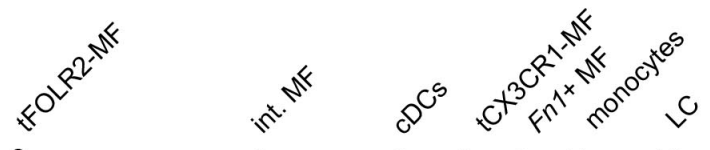
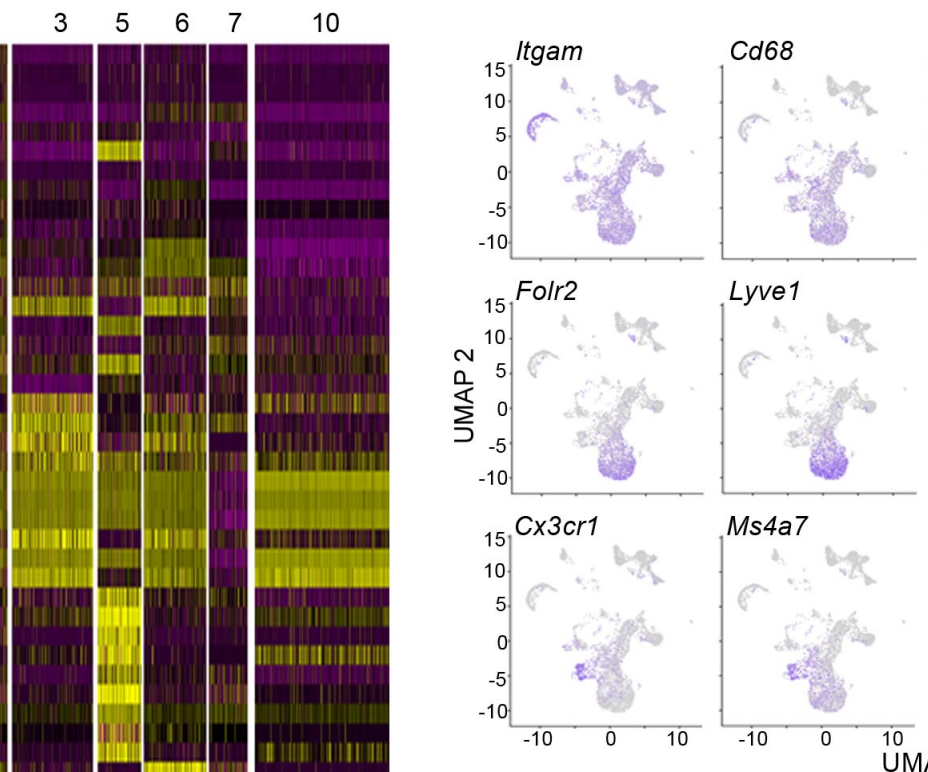

UMAP $^{-10}$
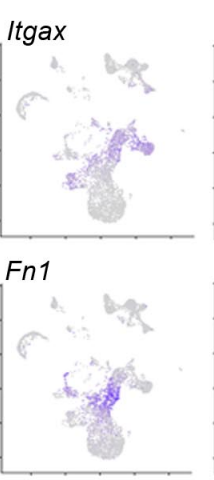

Cd209a

Ly6c2

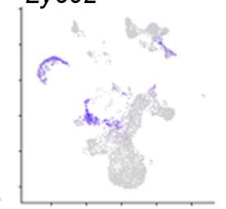

Epcam

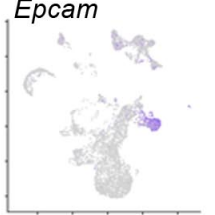

Mki67
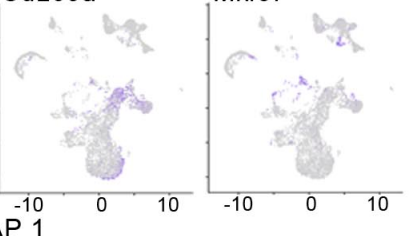

\section{f}

Co

cytosolic transport negative regulation of neuron apoptotic process macrophage differentiation positive regulation of nitric oxide regulation of sprouting angiogenesis

cellular response to thyroid hormone stimulus positive regulation of monocyte chemotaxis

C3

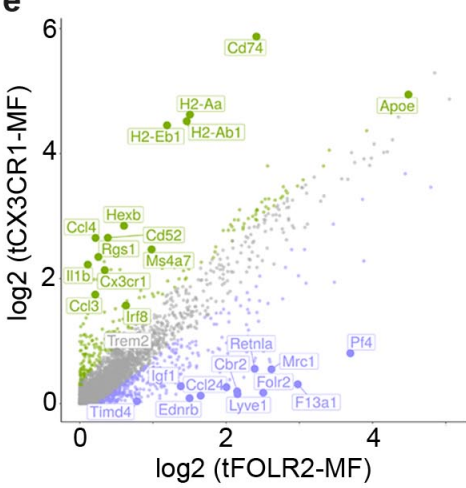

Figure 1

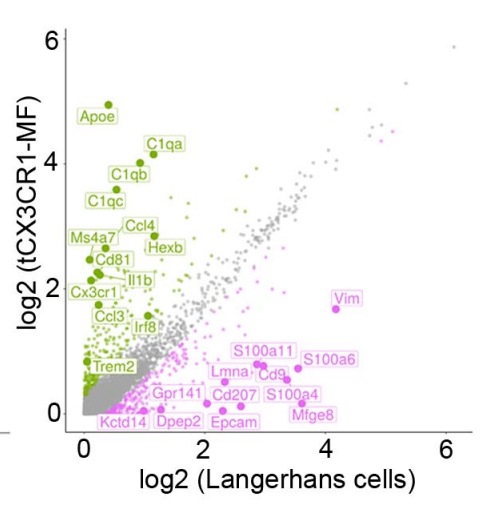

C6

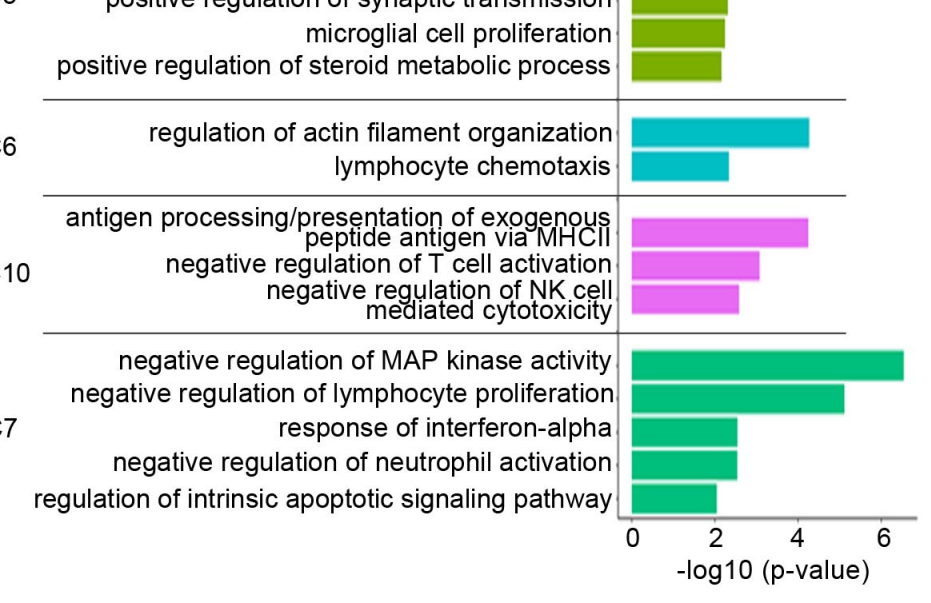


Figure 1: Characterization of mouse tongue leukocytes

(a) UMAP representation of 6773 sequenced tongue leukocytes from adult, female Bl6 mice (pool of $n=8$ mice). Data from a biologically and technically independent experiment are shown in Suppl. Fig. 1a+b. Cluster annotation was performed with SingleR (Suppl. Fig. 1c). See Suppl. Data 1+2 for complete gene lists and marker genes for all clusters. (b) Gene Set Variation Analysis (GSVA) analysis for the discrimination of macrophages and dendritic cells. One signature gene list for macrophages (derived from ${ }^{16}$ ) and one for $\mathrm{CDC}$ (derived from ${ }^{17}$ ) were used to evaluate the enrichment score for each list in the identified 19 clusters. See also Suppl. Fig. 1d for CDC1 and CDC2 gene signatures and Suppl. Data 3 for full gene lists. Cells with the highest similarity to the signature are labeled red. (c) Heatmap of top marker genes for the main mononuclear phagocyte clusters. See Suppl. Fig. 1b for a heatmap of marker genes for all clusters (d) Expression pattern of example genes laid over the UMAP for dimension reduction from Figure 1a. (e) Differentially expressed genes in tFOLR2-MF vs. tCX3CR1-MF (left) and tCX3CR1-MF vs. tongue Langerhans cells (right). Indicated genes show an increased expression of $>1.5$ with an adjusted p-value $<0.05$. (f) Gene ontology analysis of the differential expressed genes. Redundant pathways were excluded from representation. Only GO annotations involved in biological processes are shown. See Suppl. Data 4 for full list of GO terms per cluster. 
bioRxiv preprint doi: https://doi.org/10.1101/2022.02.09.479699; this version posted February $11,2022$. The copyright holder for this

preprint (which was not certified by peer review) is the author/funder, who has granted bioRxiv a license to display the preprint in perpetuity. It is made available under aCC-BY 4.0 International license.

(

b
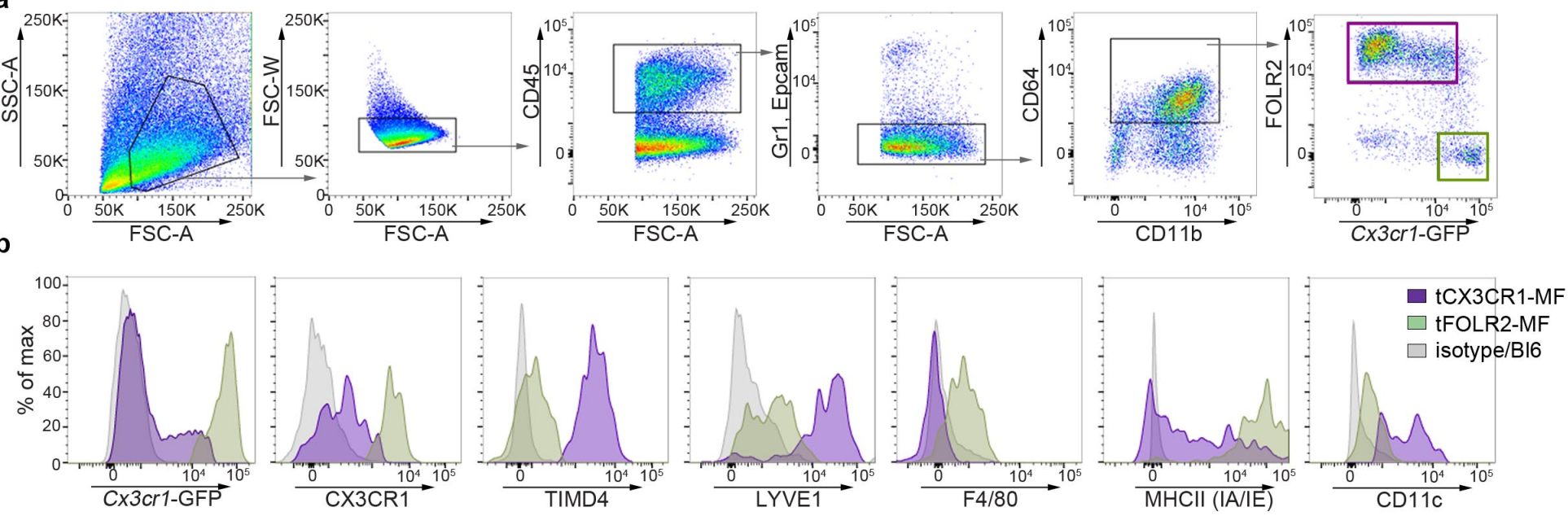

c
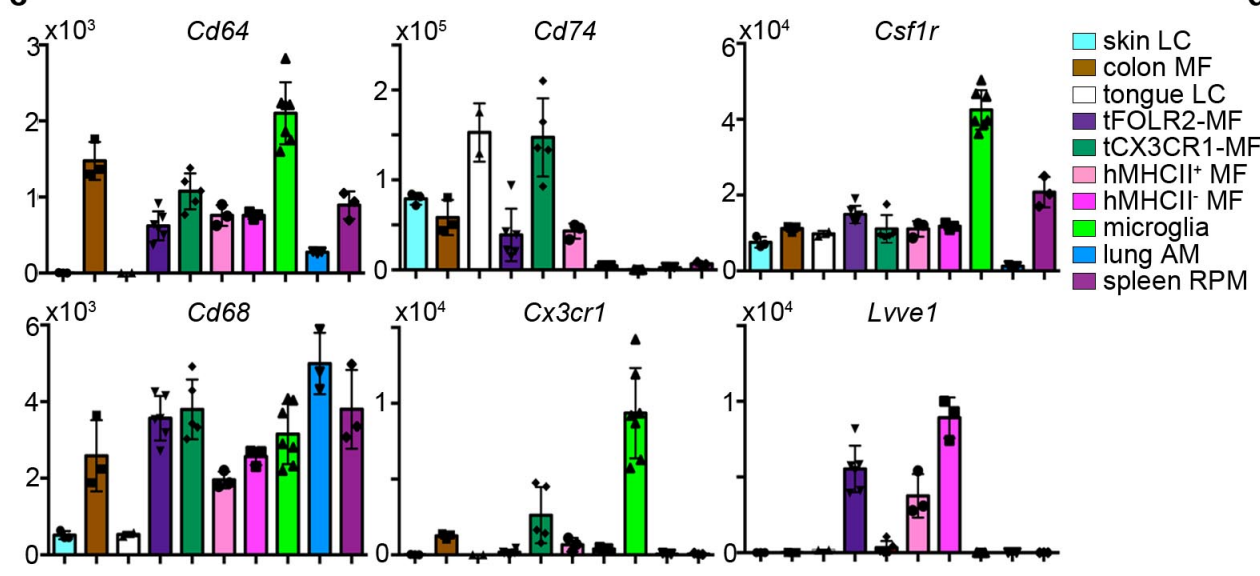

d
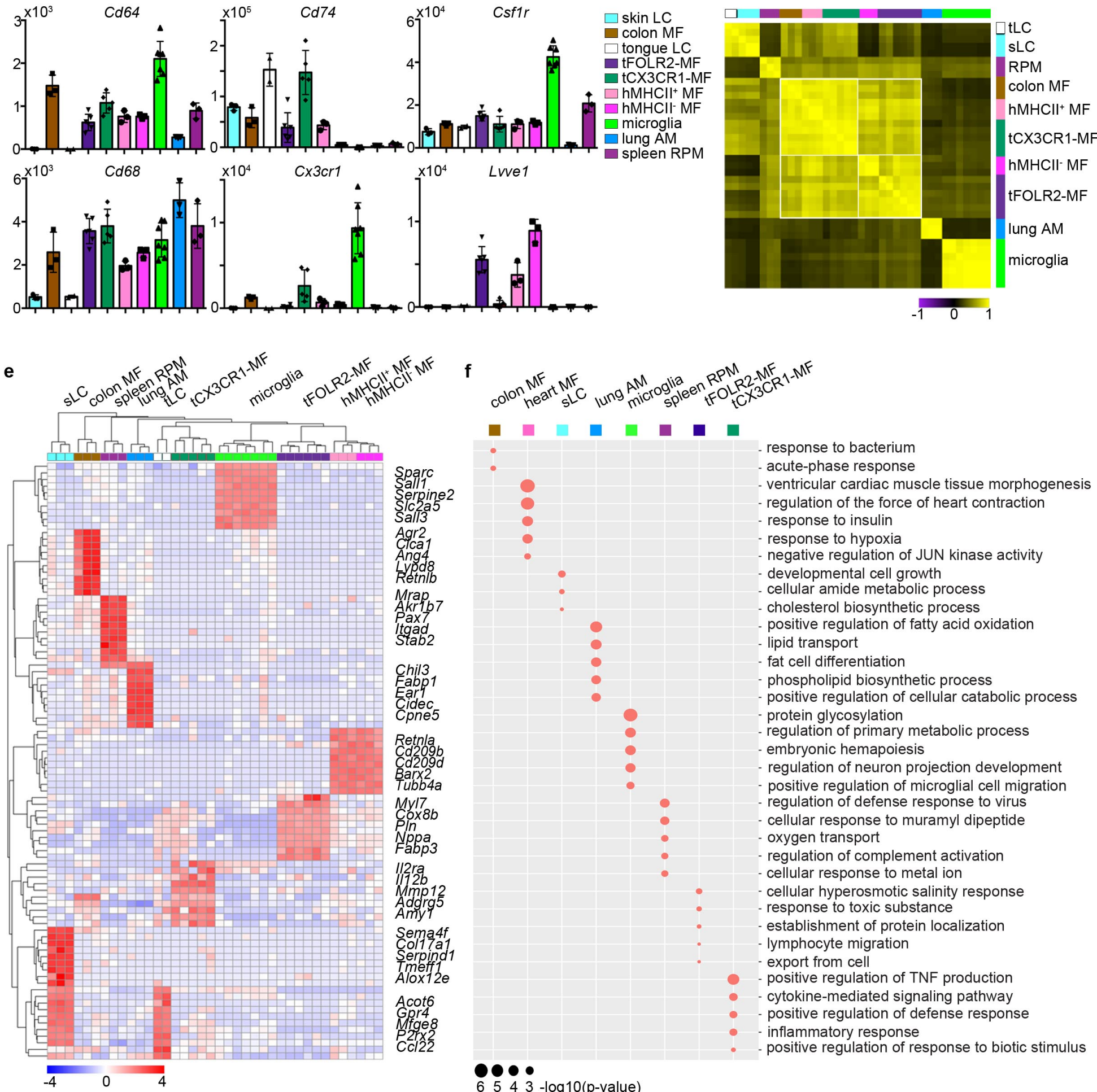

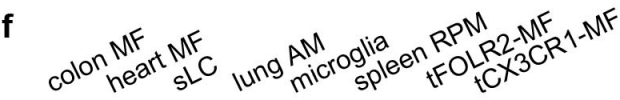

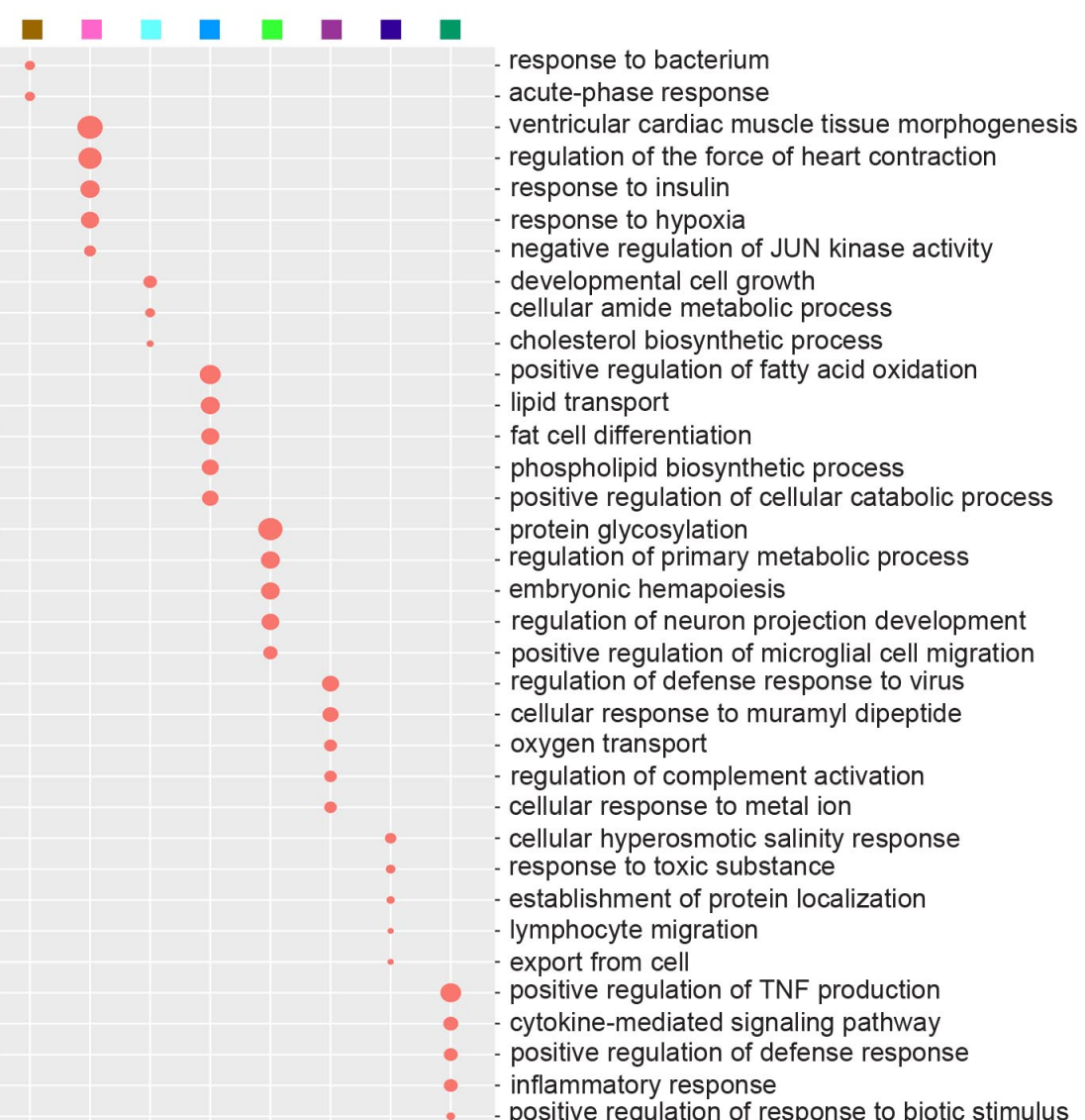

Figure 2

$6543-\log 10$ (p-value) 
Figure 2: Tissue-specific transcriptomic identity of tongue macrophages

(a) Exemplary flow cytometry analysis for tCX3CR1-MF and tFOLR2-MF in Cx3cr1 ${ }^{\mathrm{Gfp} /+}$ mice.

(b) Shown are histogram expression patterns for Cx3cr1-Gfp, CX3CR1, TIMD4, LYVE1, F4/80, MHCII and CD11C on tFOLR2-MF (violet) and tCX3CR1-MF (green). Either isotype controls or wild-type BI6 mice were used to control for antibody stain or GFP signals, respectively. (c) Different tissue resident macrophage populations were isolated by FACS (see Suppl. Fig. 3 for gating strategy) and analyzed by bulk RNA sequencing. Normalized read counts for important macrophage genes are shown across subsets. See also Suppl. Data 5 for normalized read counts. (d) Sample-wise expression correlation analysis of the different macrophage subsets is shown. Color code as indicated in c. (e) Heatmap of upregulated genes across macrophage populations. The top 10 upregulated genes per population compared to all other populations are depicted. See also Suppl. Data 6 for full list of upregulated genes. (f) Shown are GO annotations of biological processes that are enriched in specific macrophage subsets. Note that tLC showed no specific enrichment and are therefore not represented in the graph. 
a adult tongue - saggital section

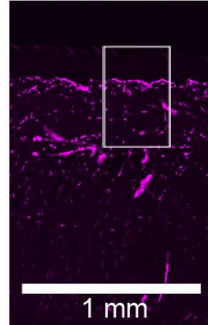

$1 \mathrm{~mm}$
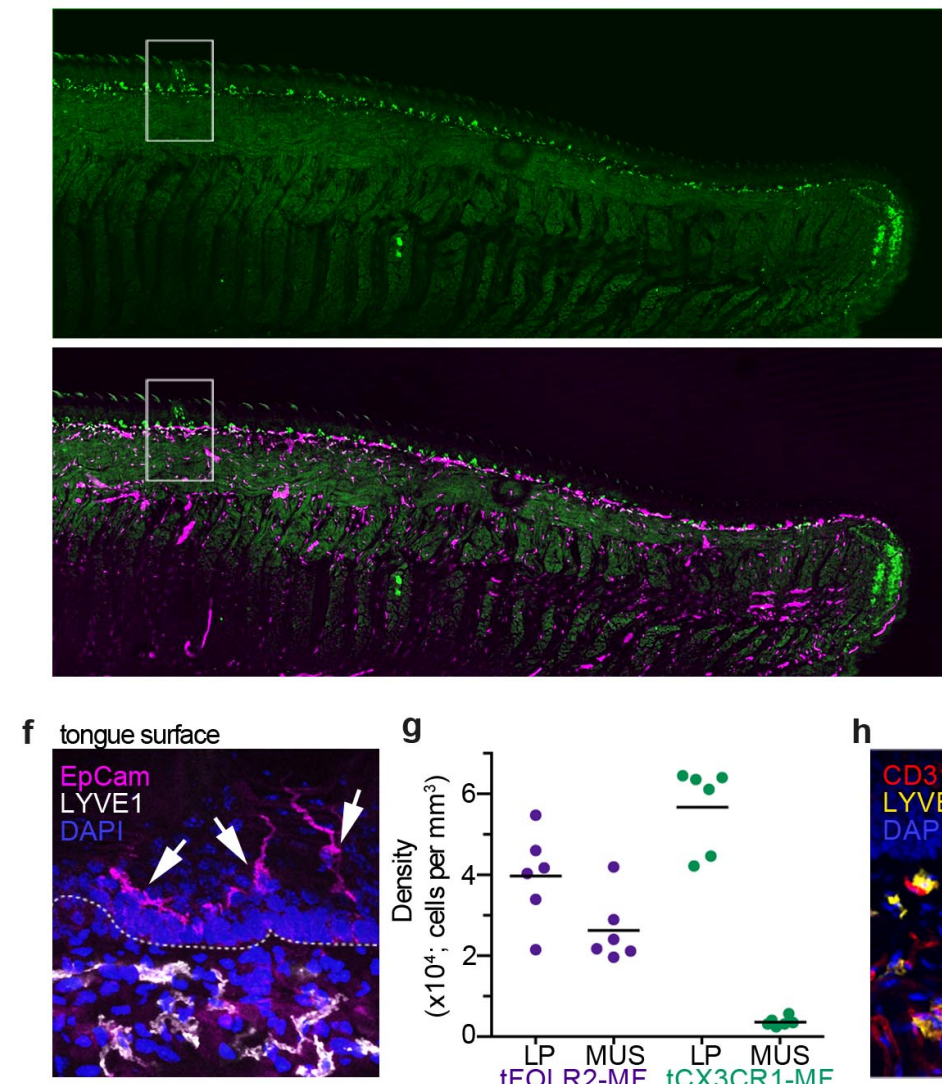

\section{g}

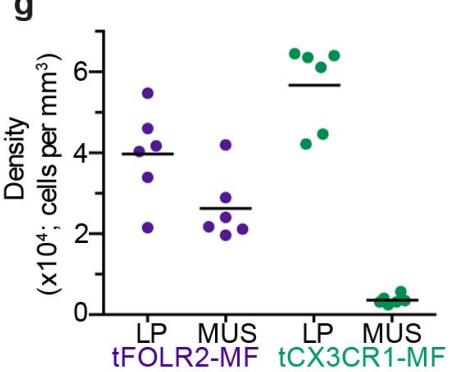

h

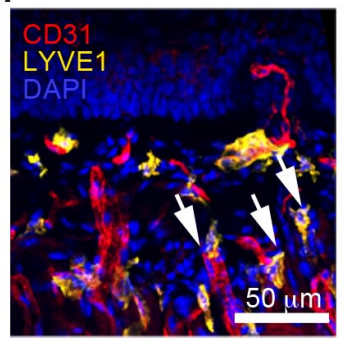

C
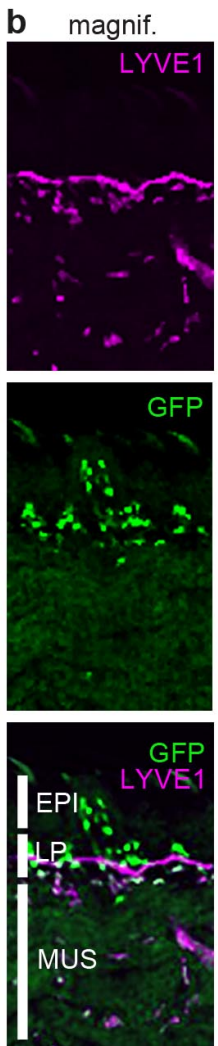

\section{$20 \mu \mathrm{m}$}
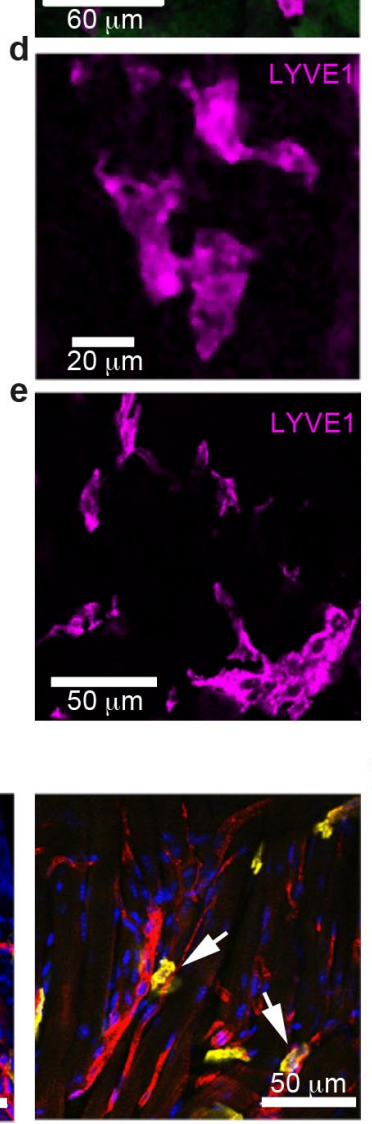

i deep muscle

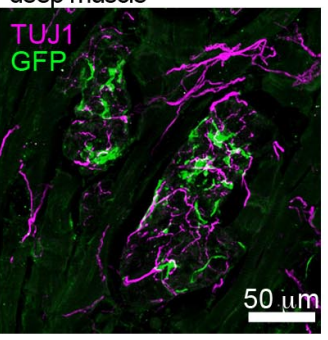

k
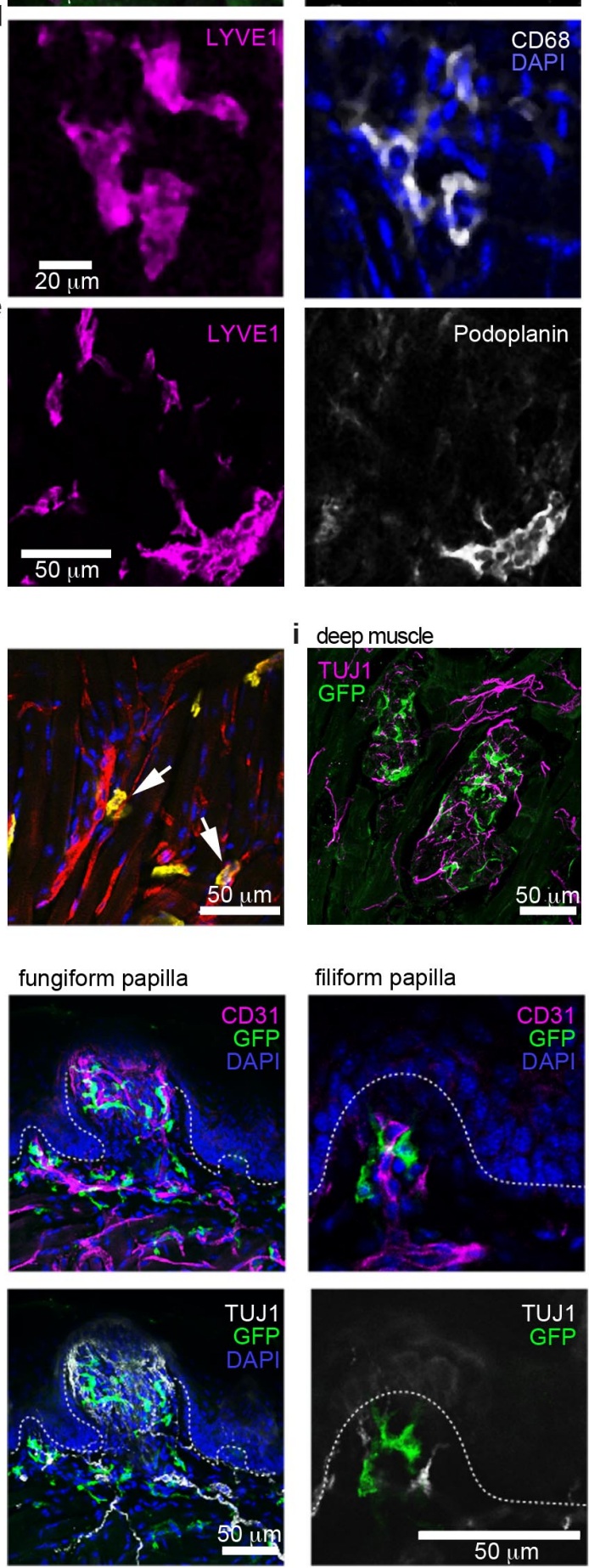

Figure 3

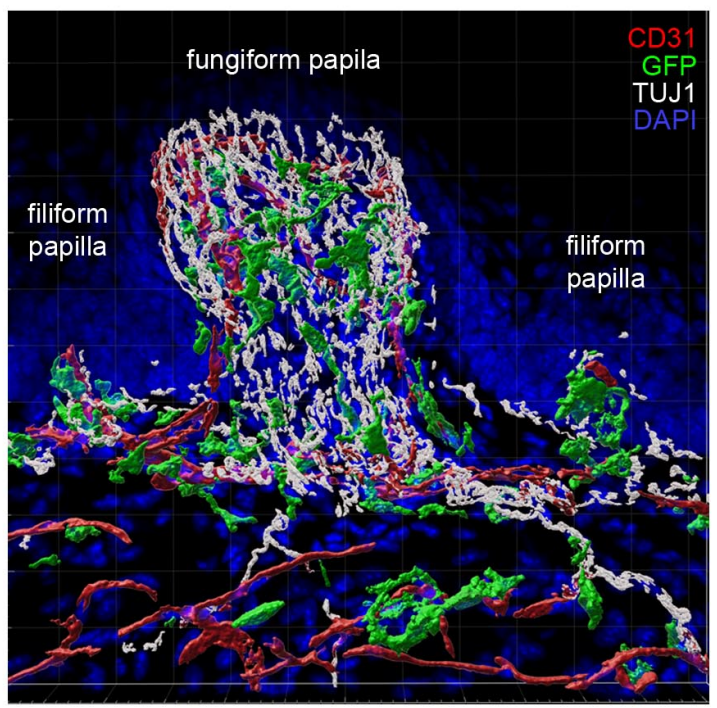


Figure 3: Distinct localization of mouse tongue macrophages

(a) Panoramic image of a tongue sagittal section from a perfused $C \times 3 c r 1^{\mathrm{Gfp} /+}$ mouse. The tongue was stained for anti-GFP (CX3CR1; green) and anti-LYVE1 (violet). (b) Magnification of the area depicted in (a) that includes a fungiform papilla with annotation of different tissue layers. EPI = epidermis, LP = lamina propria, MUS = muscle. See also Suppl. Fig. 4 for definition of layers. (c) Co-staining of anti-GFP (green) and anti-LYVE1 (violet) with antiCD68 (white). The dashed white line indicates the border between the epidermis and the lamina propria. Green arrows indicate $C x 3 c r 1-\mathrm{GFP}^{+} \mathrm{CD} 68^{+}$cells, while violet arrows highlight LYVE $1^{+} \mathrm{CD} 68^{+}$macrophages. (d) High magnification of LYVE1 $1^{+}$cells (violet) stained with anti-CD68 (white) and DAPI (blue). (e) Discrimination of podoplanin ${ }^{+}$(white) lymphatics from LYVE $^{+}$(violet) podoplanin cells. (f) Anti-Epcam (violet) staining identifies Langerhans cells in the epidermis of the tongue. Sections were stained with anti-Lyve1 (white) and DAPI (blue). (g) Quantification of tFOLR2-MF and tCX3CR1-MF in lamina propria (LP) and muscle layer (MUS) in adult female mouse tongues. Each dot represents one animal. See also Suppl. Fig. 4. (h) Proximity of $\mathrm{LYVE}^{+}$(yellow) cells to $\mathrm{CD} 31^{+}$(red) blood vessels. (i) Rare Cx3cr1-GFP (green) cell clusters could also be detected in innervated Tuj $1^{+}$(violet) areas in posterior regions of the tongue. (j) $3 \mathrm{D}$ reconstruction of $C \times 3 c r 1^{\mathrm{Gfp} /+}$ tongue tissue sections stained for anti-CD31 (red), anti-Tuj1 (white), anti-GFP (Cx3cr1; green) and DAPI (blue). (k) Localization of tCX3CR1-MF in fungiform (right) and at the base of filiform (left) papillae. Sections were stained for anti-CD31 (violet), anti-Tuj1 (white), anti-GFP (Cx3cr1; green) and DAPI (blue). 
bioRxiv preprint doi: https://doi.org/10.1101/2022.02.09.479699; this version posted February 11,2022 . The copyright holder for this

preprint (which was not certified by peer review) is the author/funder, who has granted bioRxiv a license to display the preprint in perpetuity. It is made available under aCC-BY 4.0 International license.

a
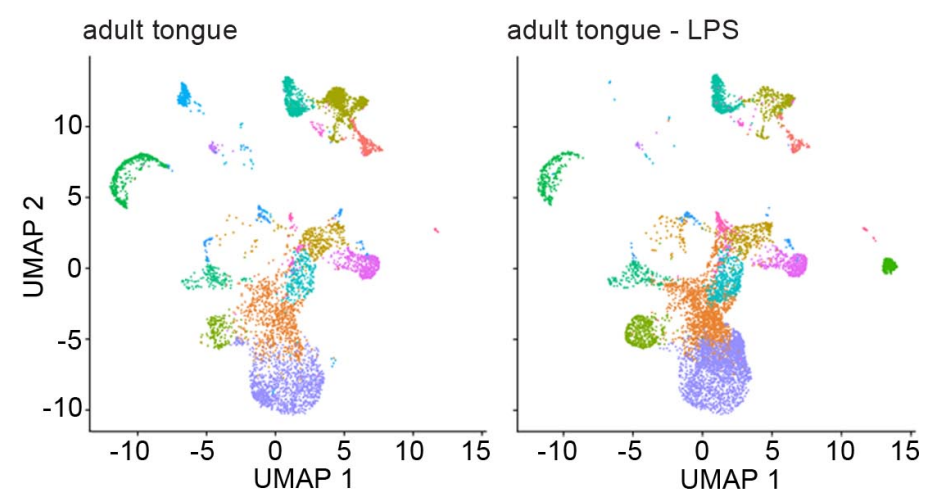

C
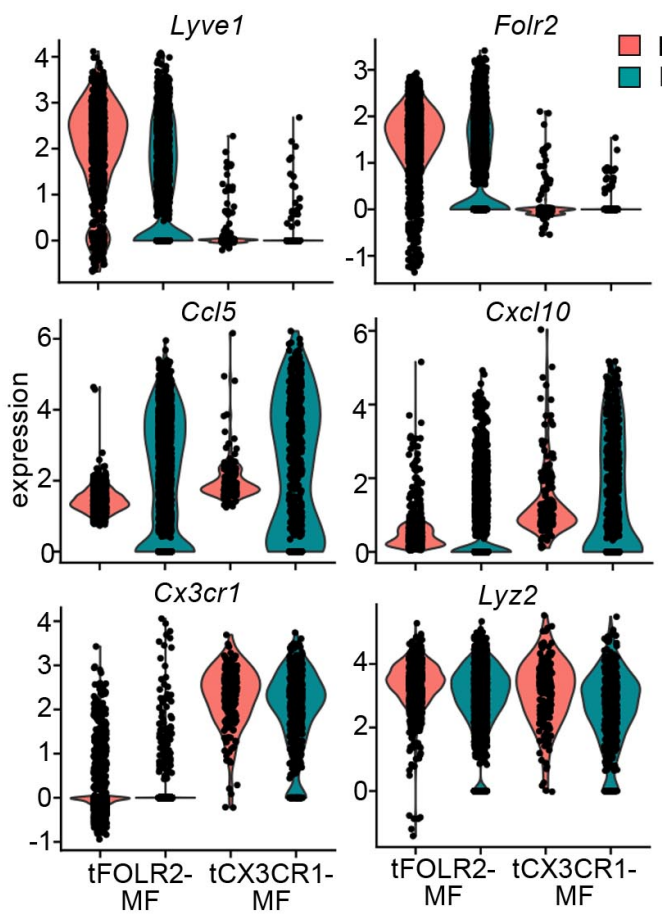

b
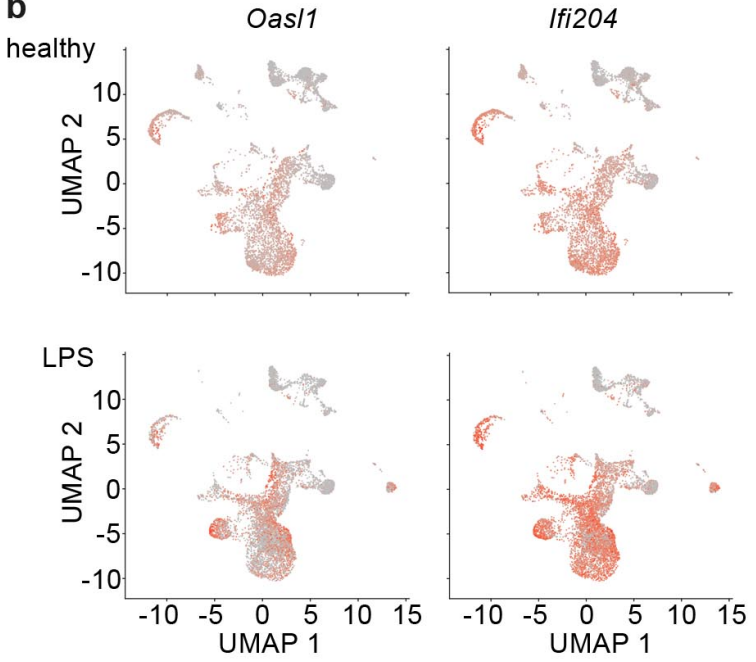

d

e

upregulated after LPS treatment

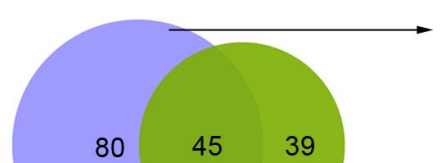

Nfkb signaling pathway. acute inflammatory response. response to LPS response to external stimulus immune system process

regulation of innate immune response regulation of response to stress. cellular response to IFNg cllular response to IFNb cellular response to chemical stimulus

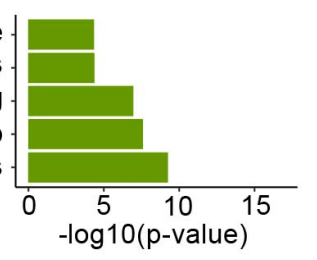

downregulated after LPS treatment
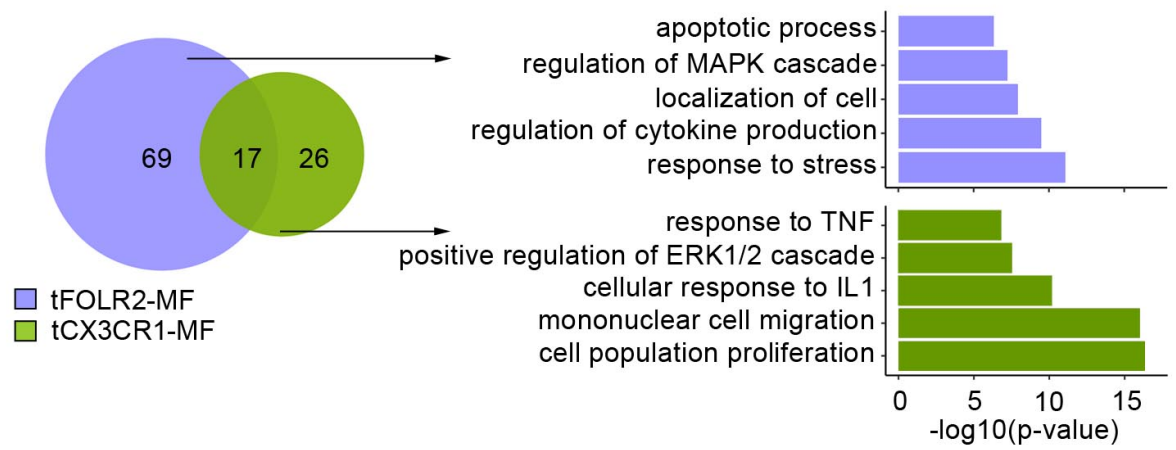

Figure 4 
Figure 4: Inflammatory response of tongue macrophages to systemic LPS challenge (a) Female BI6 mice were intraperitonally injected with $1 \mathrm{mg} / \mathrm{kg}$ LPS and tongue CD45 leukocytes were FACS purified 6 hours after injection (pool of 6 mice). In total, 8165 LPSexposed tongue leukocytes were sequenced and the data was integrated with the existing adult analysis in order to allow population comparison. Shown are UMAPs for adult cells (left) and LPS-treated cells (right). (b) Gene expression pattern of Oas/1 and Ifi204 in healthy and LPS-treated tongue leukocytes. (c) Violin blots showing marker gene expression patterns in untreated (red) and LPS treated (green) tFOLR2-MF and tCX3CR1-MF. (d) Number of upand down-regulated genes in tFOLR2-MF (violet) and tCX3CR1-MF (green) after LPS injection. The full list of DEGs can be found in Suppl. Data 7. (e) GO enrichment analysis of the DEGs. Only GO annotations involved in biological processes are shown. 
bioRxiv preprint doi: https://doi.org/10.1101/2022.02.09.479699; this version posted February 11, 2022. The copyright holder for this

preprint (which was not certified by peer review) is the author/funder, who has granted bioRxiv a license to display the preprint in perpetuity. It is made available under aCC-BY 4.0 International license.

a

age

E17.5

b

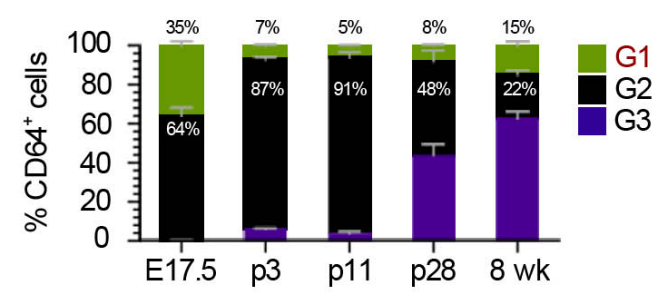

C

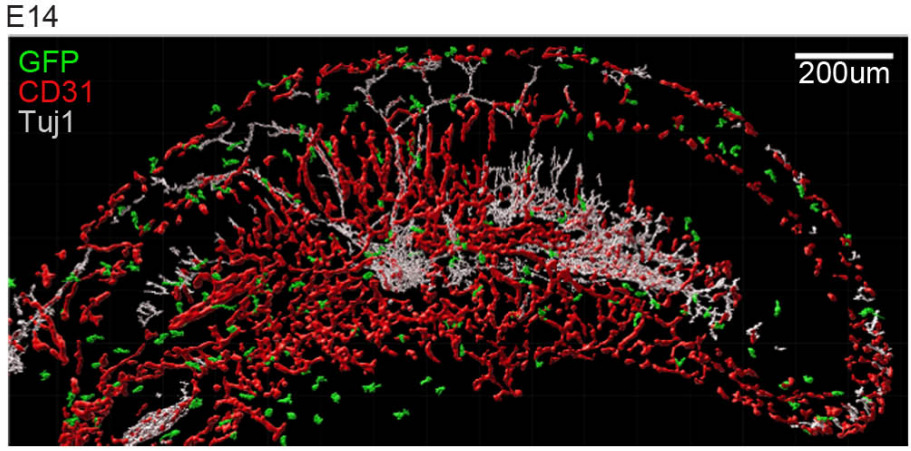

po
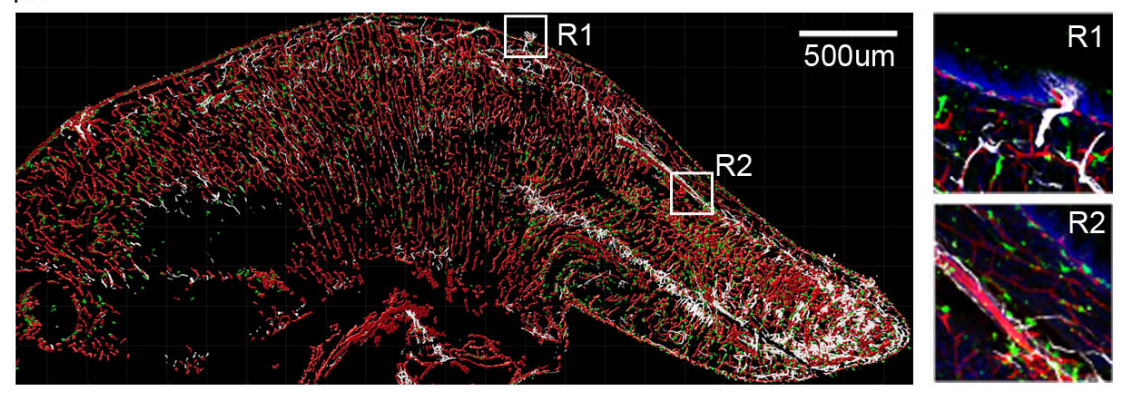

p3

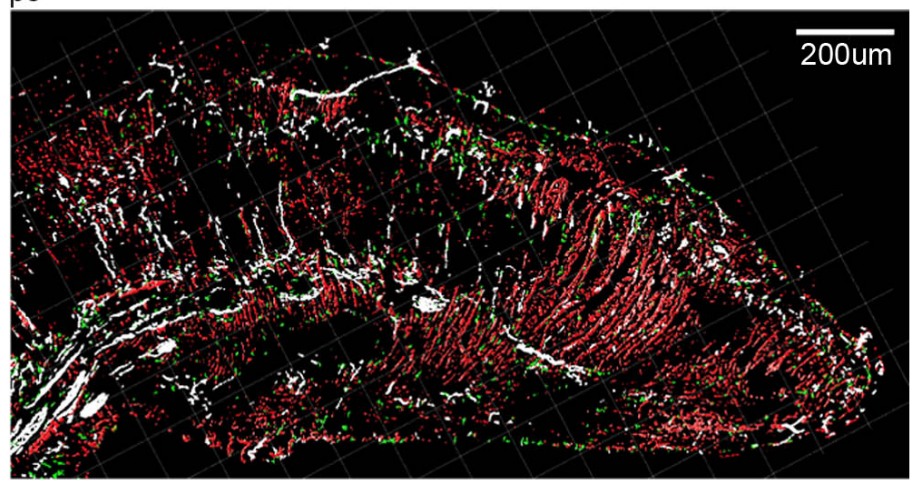

Figure 5 
Figure 5: Tongue macrophage distribution during development

(a) Flow cytometry analysis of tongue leukocytes isolated from $\mathrm{C} \times 3 \mathrm{cr} 1^{\mathrm{Gfp} /+}$ mice at different embryonic $(E)$ and postnatal $(p)$ stages of development. Cells were pre-gated for $C D 45^{+}$ Epcam $^{-} \mathrm{Gr}^{-}$. (b) Distribution of Cx3cr1-GFP ${ }^{+}$FOLR2 $^{-}$(G1), Cx3cr1-GFP ${ }^{+}$FOLR2 $^{+}$(G2) and Cx3cr1-GFP ${ }^{-}$FOLR2 ${ }^{+}$(G3) cells out of $\mathrm{CD} 4^{+}$cells. 5-7 animals per time point were used. (c) $3 D$ reconstructions of sagittal tongue sections stained with anti-GFP (green), anti-CD31 (blood vessels; red) and anti-TUJ1 (neurons; white) from E14, p0 and p3 Cx3cr1 ${ }^{\mathrm{Gfp} /+}$ reporter mouse tongues. 
bioRxiv preprint doi: https://doi.org/10.1101/2022.02.09.479699; this version posted February 11,2022 . The copyright holder for this

preprint (which was not certified by peer review) is the author/funder, who has granted bioRxiv a license to display the preprint in perpetuity. It is made available under aCC-BY 4.0 International license.

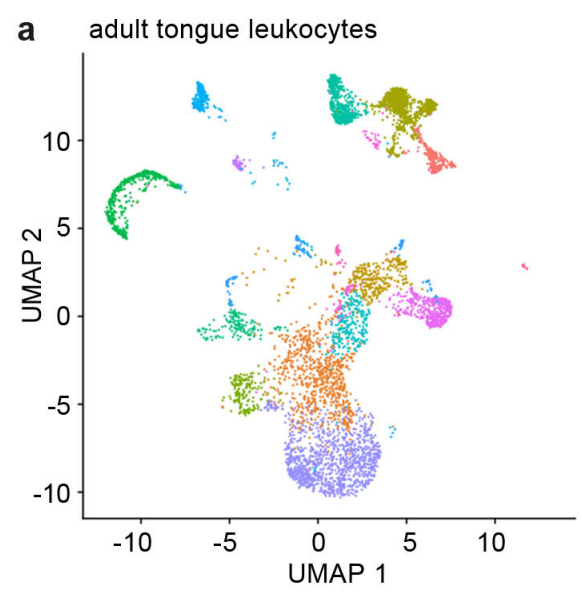

C
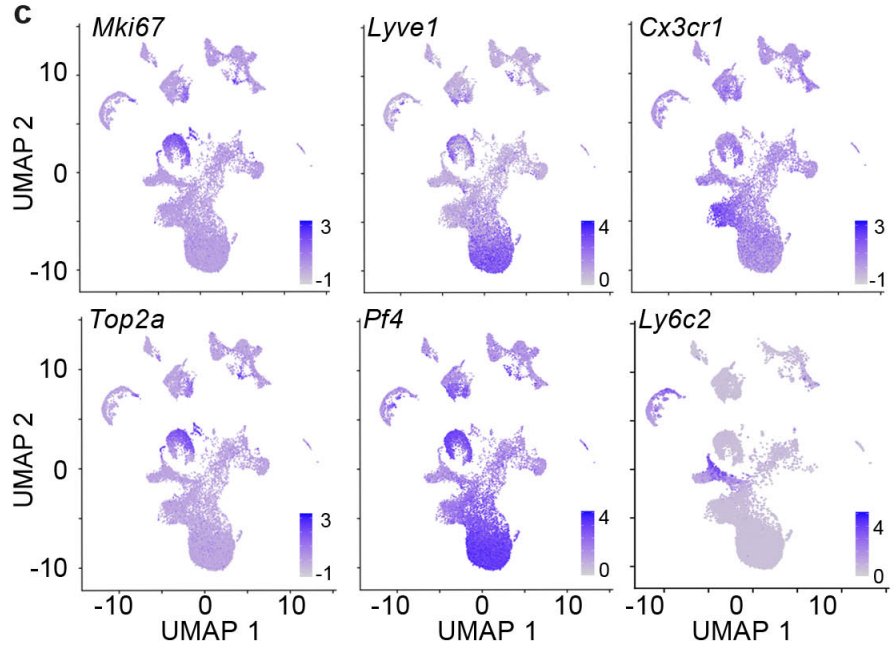

$\mathbf{f}$
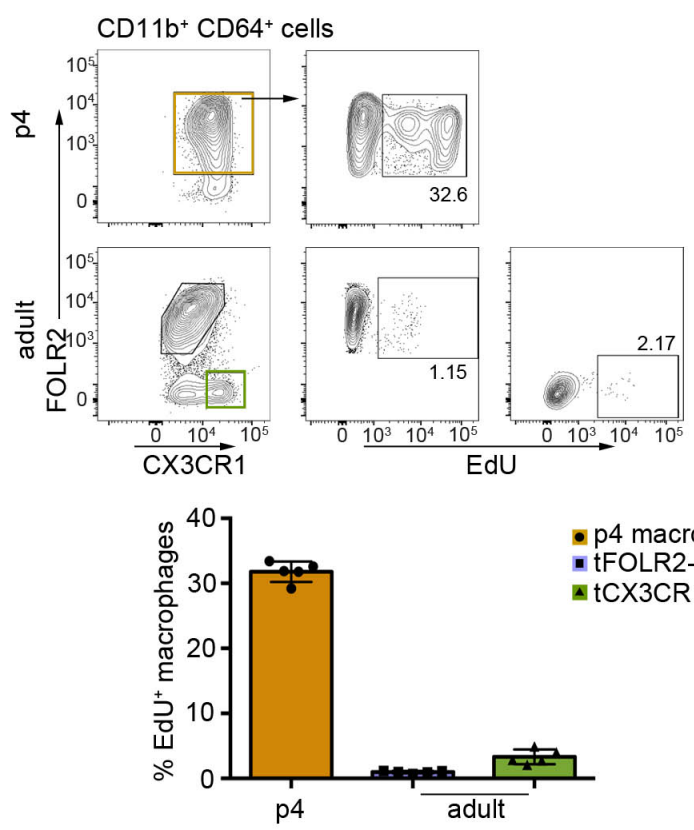

Figure 6 newborn (p3) tongue leukocytes

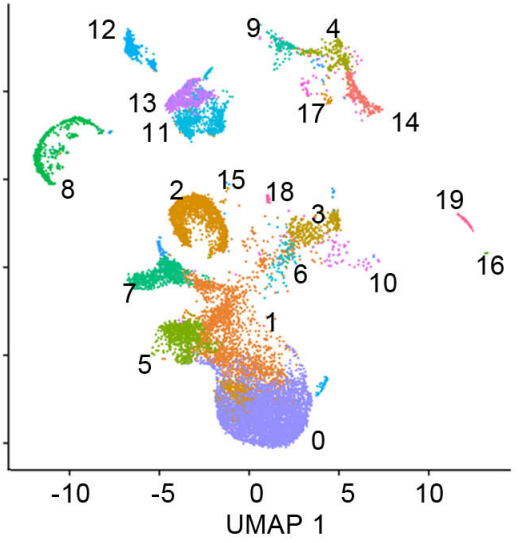

d

$\stackrel{3 \mathrm{D}}{\longrightarrow}$

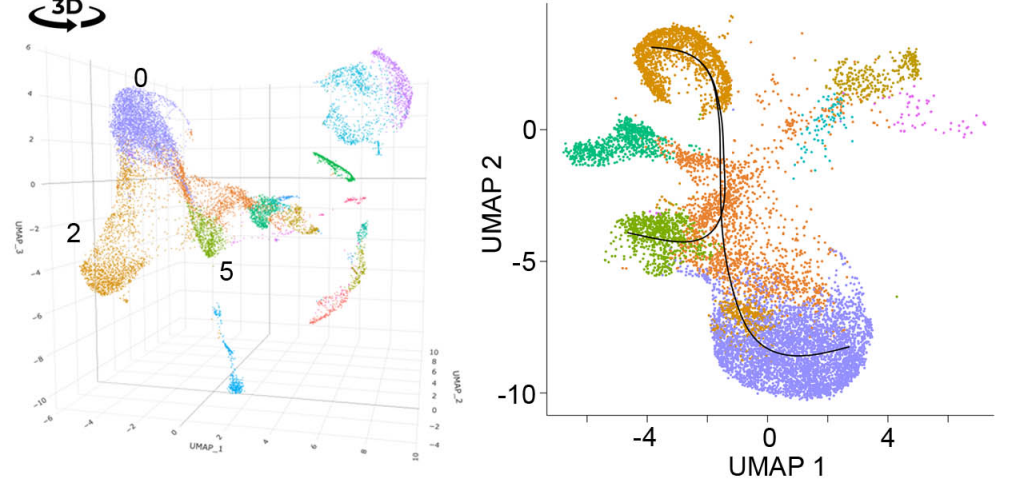

g
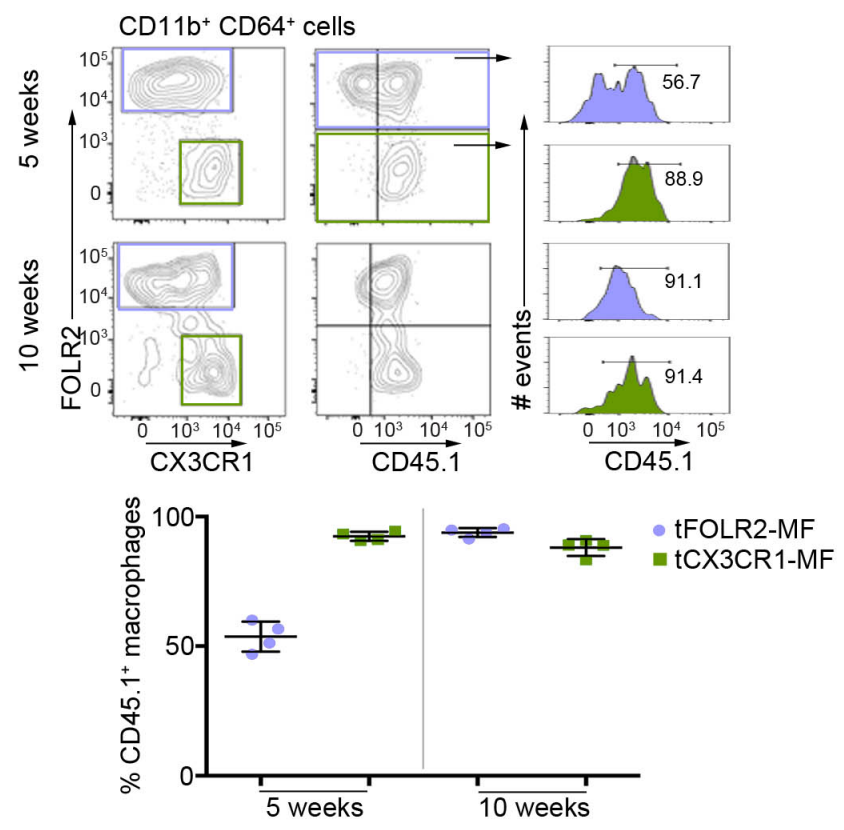

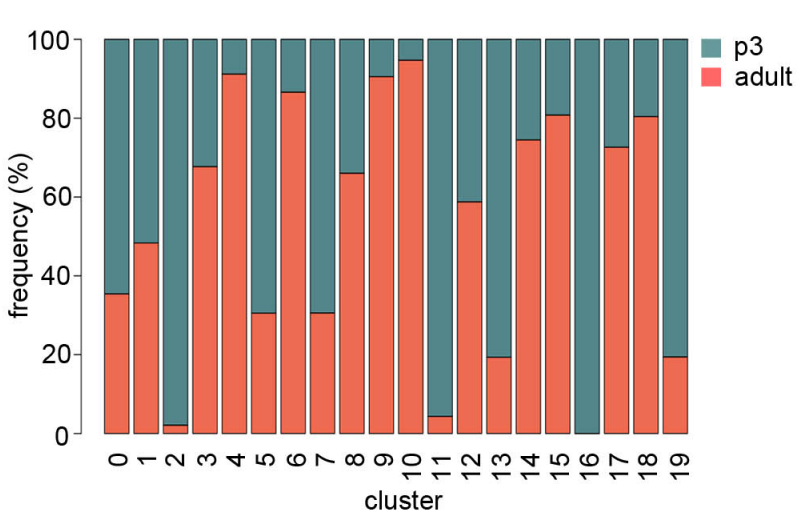

e 
Figure 6: Transcriptomic analysis of hematopoietic tongue cells from newborn mice

(a) $\mathrm{CD} 45^{+}$tongue leukocytes were isolated by FACS from newborn p3 mice. The purified cells were subjected to scRNA-seq and a total of 13898 cells were sequenced. The early postnatal data was integrated with the adult scRNA-seq dataset shown in Fig. 1 for population comparison. Shown are UMAPs for adult (left) and newborn cells (right). (b) Cell frequencies for each cell cluster in adult and newborn mice. (c) Expression levels of example genes in newborn cells shown in the UMAP. (d) 3D UMAP visualization reveals the merging of proliferating cluster 2 cells with cluster 0 cells. The 3D html file is provided in Suppl. Data 8. (e) Slingshot analysis was used to model the developmental trajectories of tongue macrophages. (f) In vivo EdU proliferation assay of adult and newborn tongue leukocytes. EdU was injected and tongue cells were isolated 24 hours after injection. Each dot represents one independent animal. The experiment was performed once. (g) CD45.2/2 animals were lethally irradiated ( $9.5 \mathrm{~Gy})$ and reconstituted with CD45.1/1 bone marrow cells. 5 weeks (left) and 10 weeks (right) after transfer, tongue cells were isolated and investigated by flow cytometry for the distribution of CD45.1+ cells within the macrophage subsets. Each dot represents one independent animal. The experiment was performed once. 
bioRxiv preprint doi: https://doi.org/10.1101/2022.02.09.479699; this version posted February 11, 2022. The copyright holder for this preprint (which was not certified by per review) is the author/funder, who has granted bioRxiv a license to display the preprint in

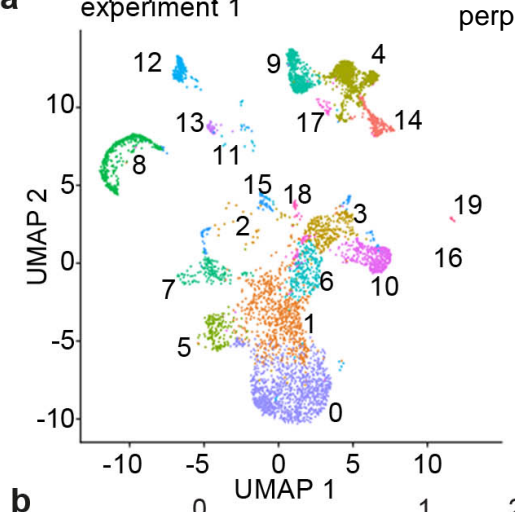
perpetexperimentade available under aCC-BY 4.0 International license.

b

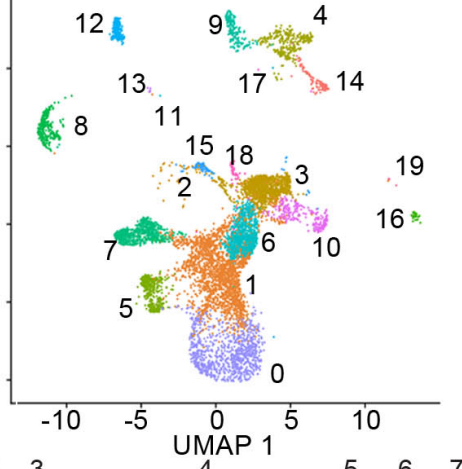

- 0. tFOLR2-MF

- 1. int. MF

2. prolif. myeloid cells

- 10. Langerhans cells

3. Dendritic cells (cDC1)

- 4. Treg

5. $\mathrm{tCX}$ 3CR1-MF

- 6. Fn1+ cells

- 7. Ly6C+monocytes

- 8. Neutrophils

- 9. ILC2

12. B cells

- 13. Mast Cells 2

- 14. NK cells

- 15. preDCs

- 16. endothelial cells

17. Rora+ T cells

- 18. Dendritic cells

- 19. fibroblasts
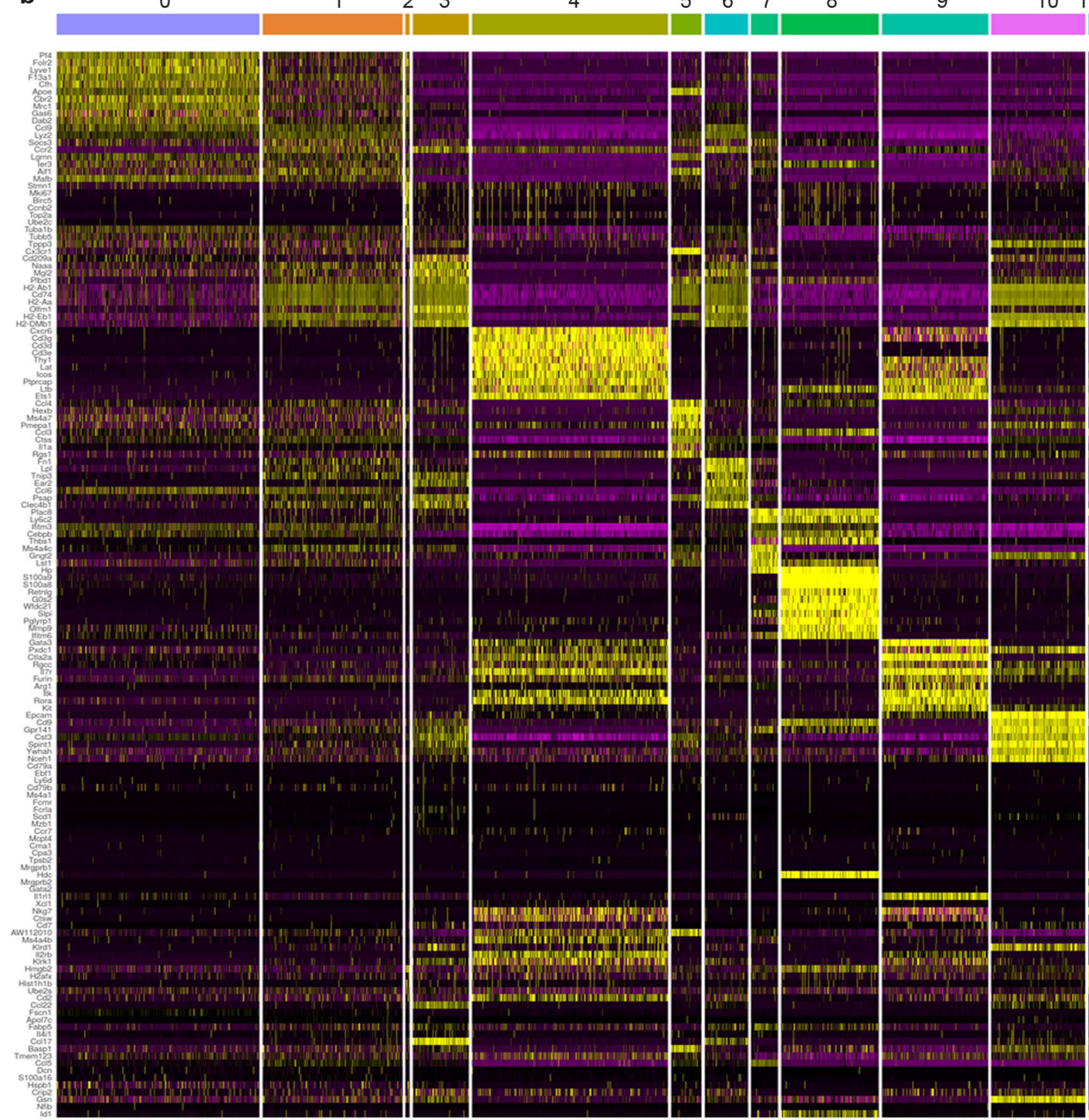

8

$10 \quad 11 \quad 12 \quad 13$

15171819
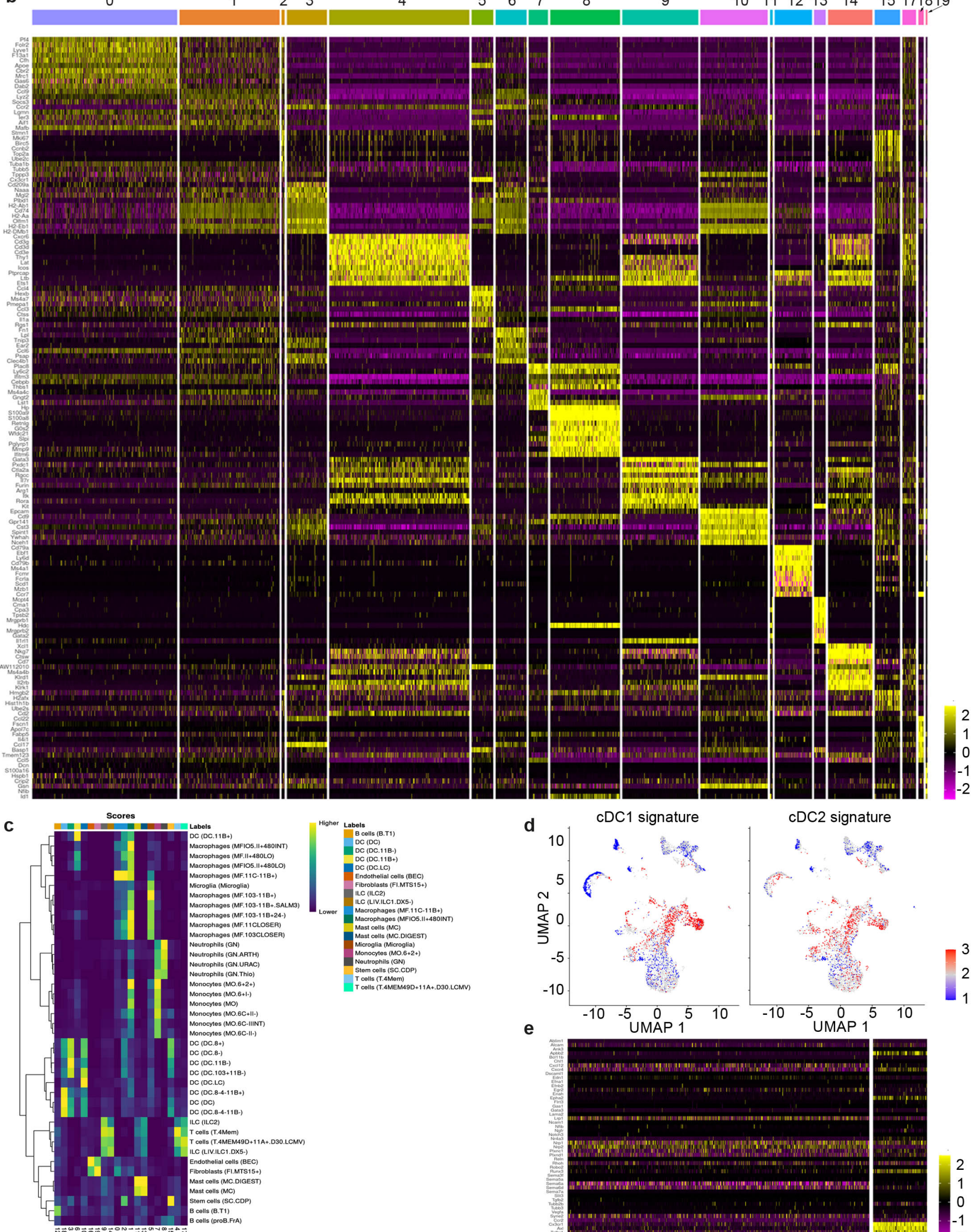

d

cDC1 signature

cDC2 signature

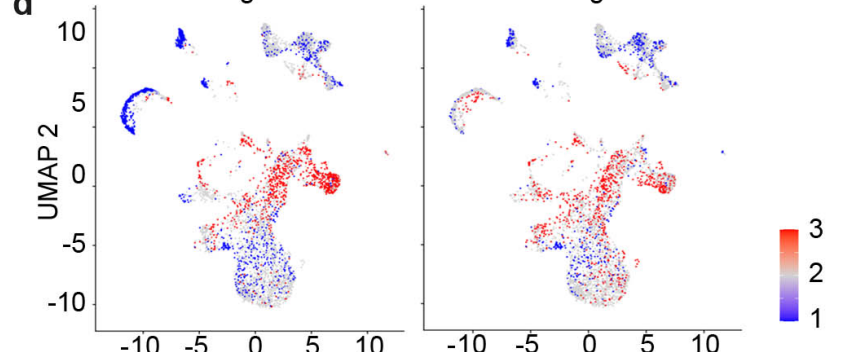

e

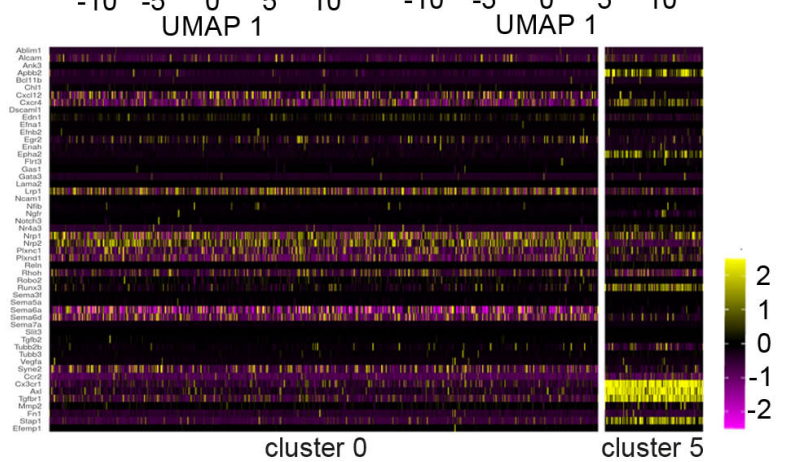


Supplementary Figure 1: Characterization of adult tongue leukocytes

(a) Biological and technical replication (experiment 2, right graph) of the scRNA-seq experiment depicted in Fig. 1 (experiment 1, left graph). For experiment 2, CD45 tongue leukocytes were isolated from female mouse tongues and 8151 cells were sequenced using the Chromium Single Cell 3' Reagent Kits v2. Experiment 2 data was integrated with the existing adult data of experiment 1 to allow population comparison. (b) Heatmap representing the top 10 marker genes for all detected clusters. Data is derived from experiment 1 shown in Fig. 1. (c) SingleR results for the annotation of cell clusters. Note that cluster 6 cells showed similarities to CD11 ${ }^{+}$DCs from Immgen (Immgen.org). (d) GSVA analysis of the CDC1 and CDC2 signature genes as defined in ${ }^{17}$. Red indicates cells with higher enrichment scores for the signature genes compared to blue. (e) Heatmap of genes involved in axon guidance. Shown are the normalized read counts in tFOLR2-MF (cluster 0) and tCX3CR1-MF (cluster 5). 
bioRxiv preprint doi: https://doi.org/10.1101/2022.02.09.479699; this version posted February $11,2022$. The copyright holder for this

preprint (which was not certified by peer review) is the author/funder, who has granted bioRxiv a license to display the preprint in perpetuity. It is made available under aCC-BY 4.0 International license.

a Tongue digested with DNase/Collagenase IV/Hyaluronidase

GFP-negative control - whole tongue

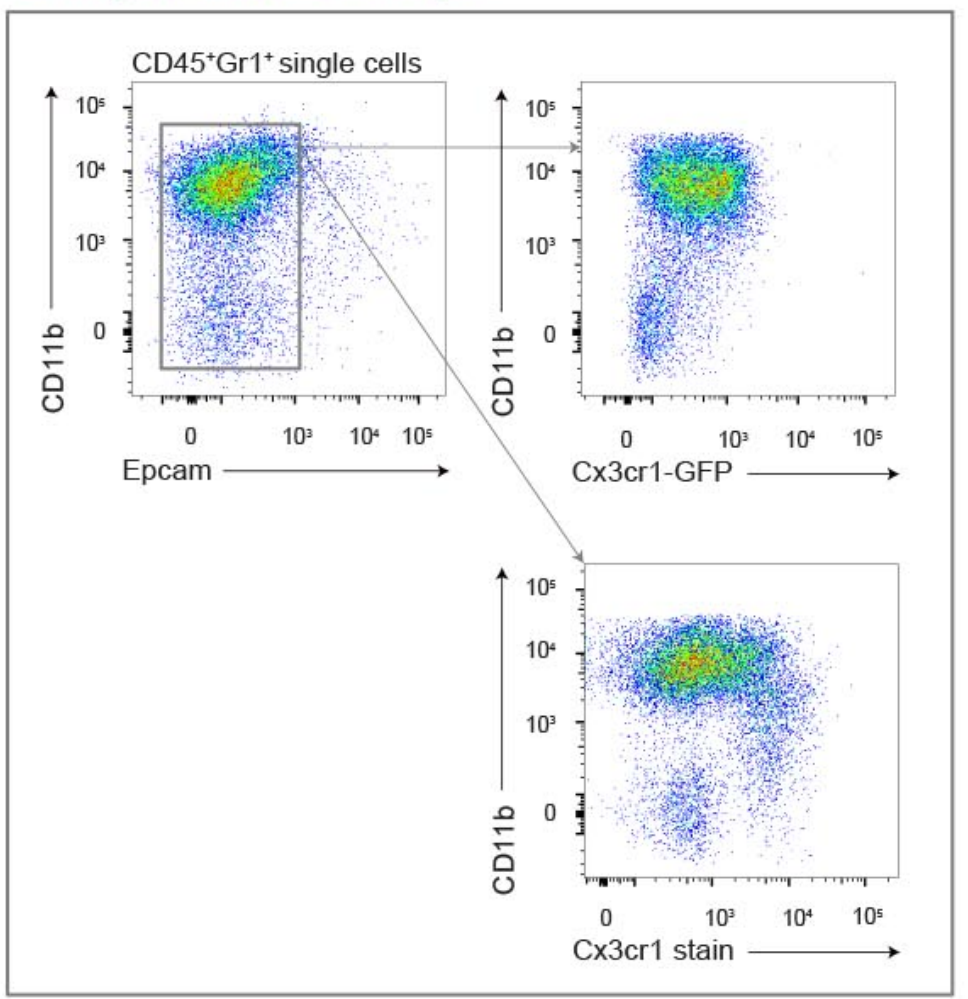

GFP-expressing mouse - whole tongue

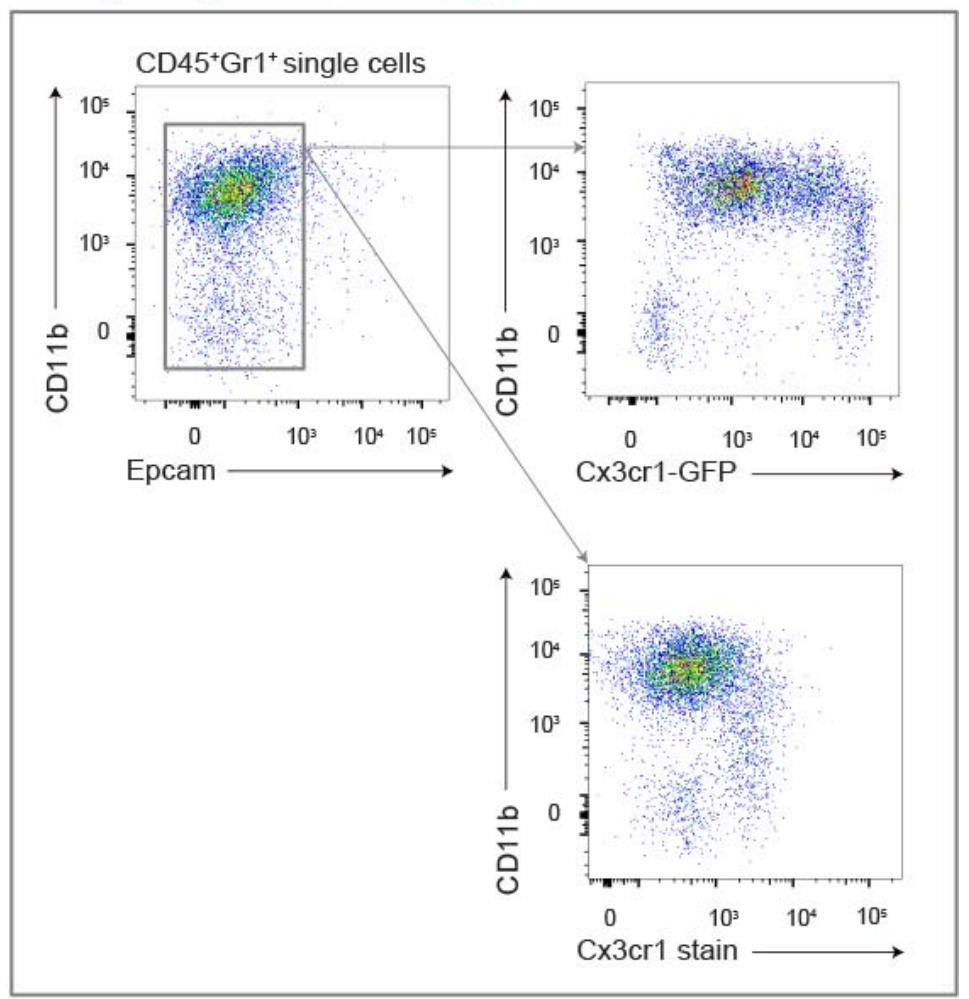

b Tongue digested with Dispase, followed by DNase/Collagenase IV/Hyaluronidase digestion

GFP-expressing mouse - epithelial layer of tongue

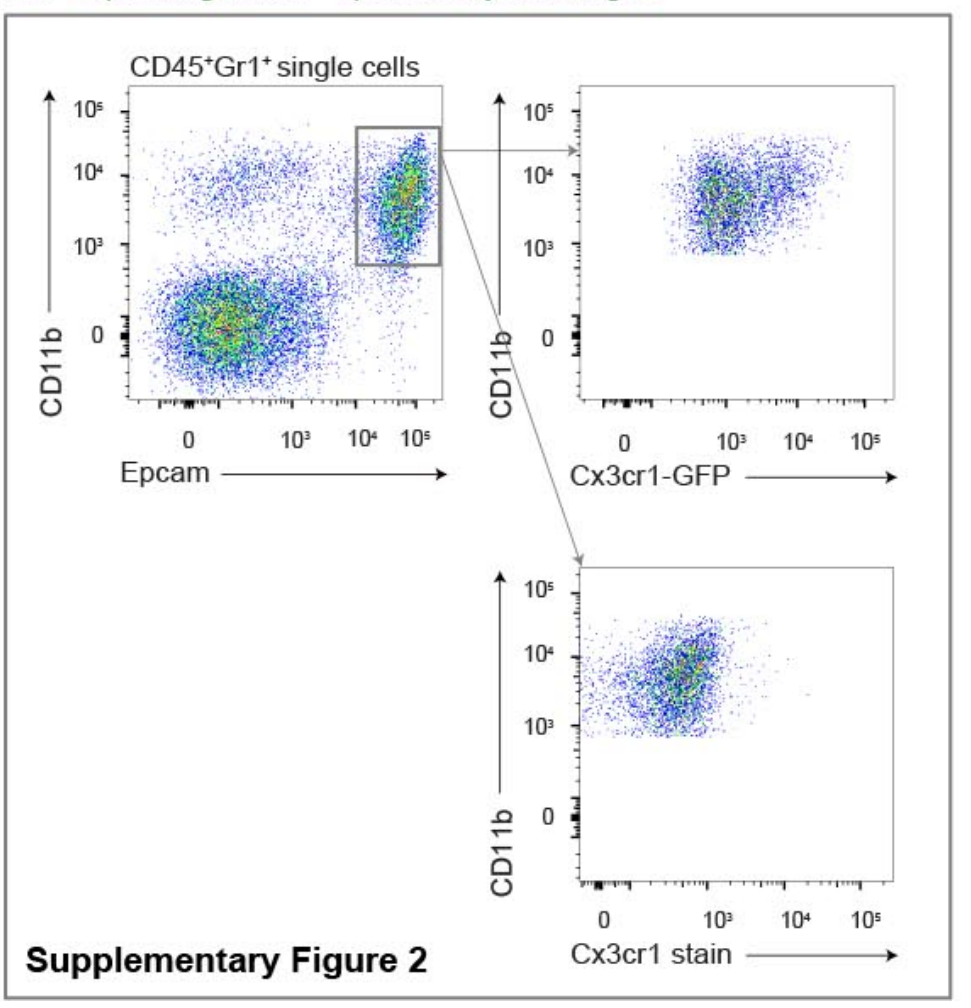

GFP-expressing mouse - muscle layer of tongue

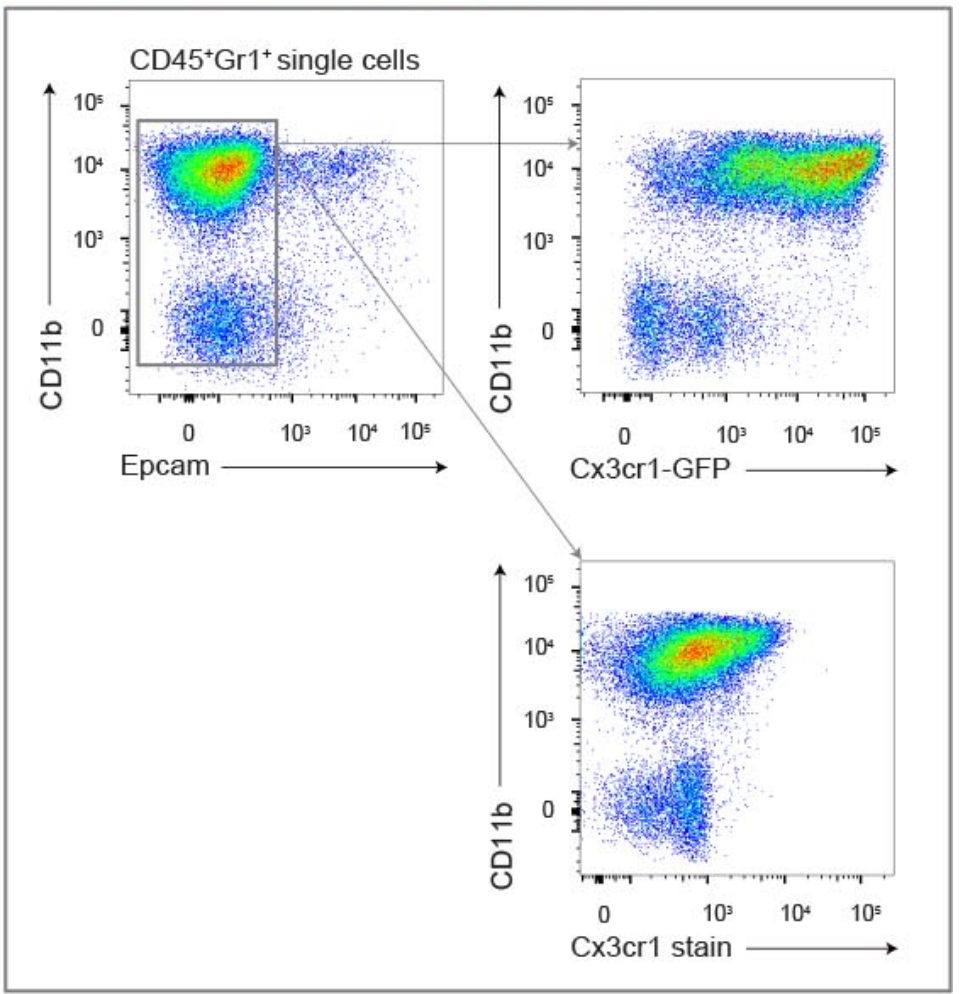


bioRxiv preprint doi: https://doi.org/10.1101/2022.02.09.479699; this version posted February 11, 2022. The copyright holder for this preprint (which was not certified by peer review) is the author/funder, who has granted bioRxiv a license to display the preprint in perpetuity. It is made available under aCC-BY 4.0 International license.

Supplementary Figure 2: Different isolation methods for the identification of tongue leukocytes

(a) Digestion of tongues from PBS perfused mice with collagenase IV, hyaluronidase and DNase. Shown are examples for BI6 mice (left) and $C \times 3 c r 1^{\text {Gfp/+ }}$ mice (right). Note the almost complete absence of $\mathrm{CD} 11 \mathrm{~b}^{+} \mathrm{Epcam}^{+}$Langerhans cells. (b) After $\mathrm{C} \times 3 \mathrm{cr} 1^{\mathrm{Gfp} /+}$ tongues were first digested with dispase, the epithelial layer was peeled off and subsequently digested with collagenase IV, hyaluronidase and DNase. With this preparation protocol, CD11 b $\mathrm{b}^{+}$Epcam $^{+}$ Langerhans cells could be detected in the epithelial layer (left), but not in the muscle layer (right). 


\section{Supplementary Figure 3}

a Gating strategy for skin Langerhans cells (skin LC)

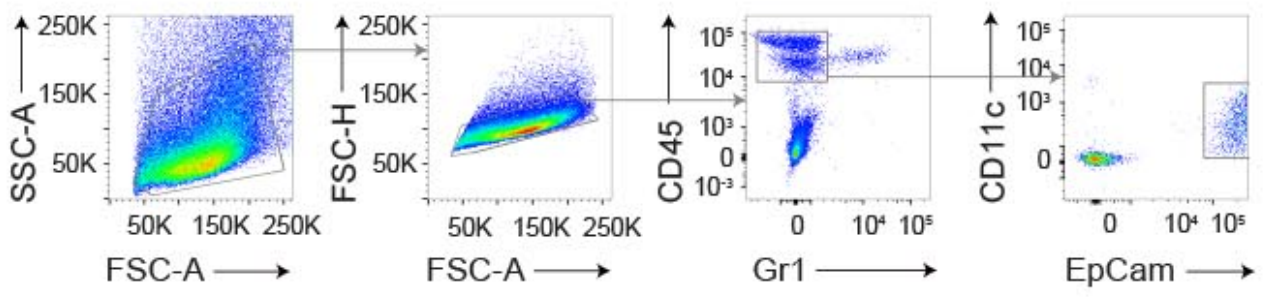

b Gating strategy for spleen red pulp macrophages (spleen RPM)

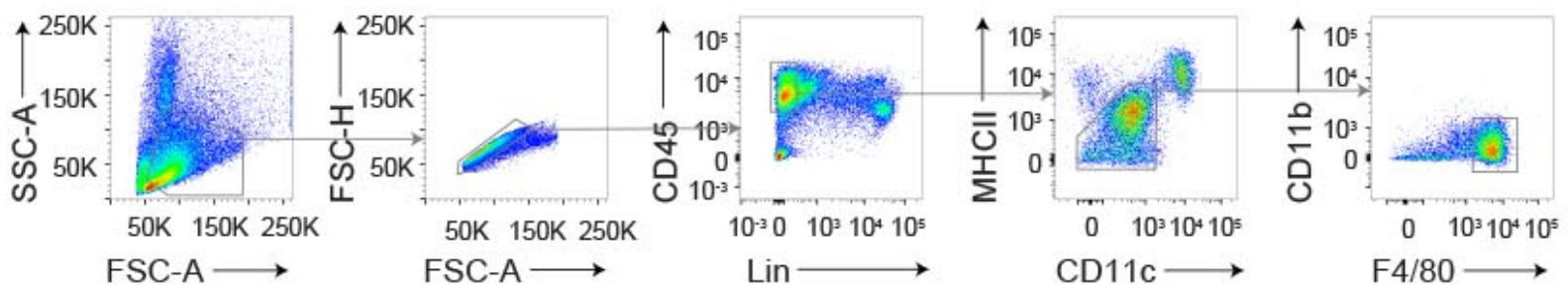

c Gating strategy for colon macrophages (colon MF)

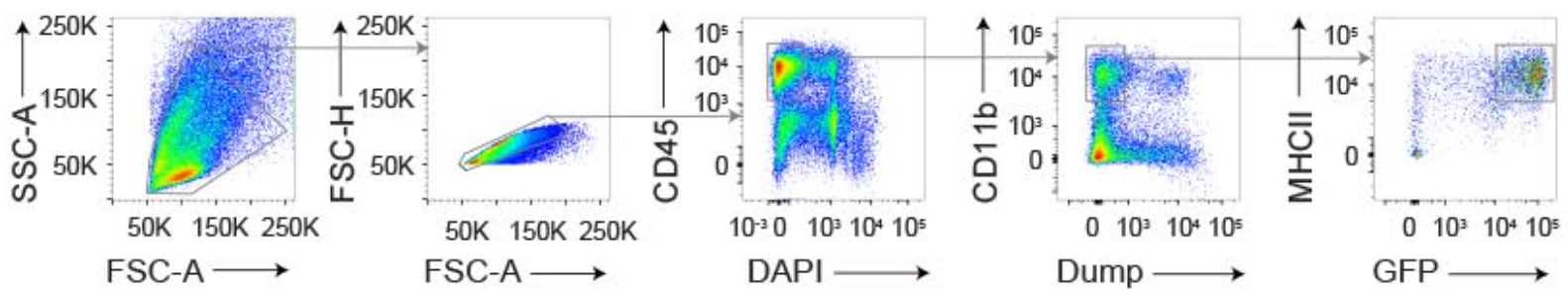

d Gating strategy for heart macrophages (heart $\mathrm{MHC} \mathrm{Il-and} \mathrm{MHC} \mathrm{II}^{+}$)

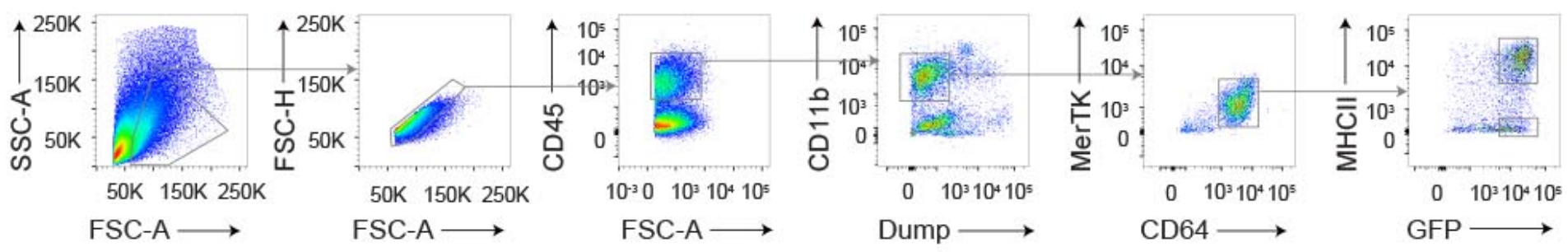

e Gating strategy for lung alveolar macrophages (lung AM)

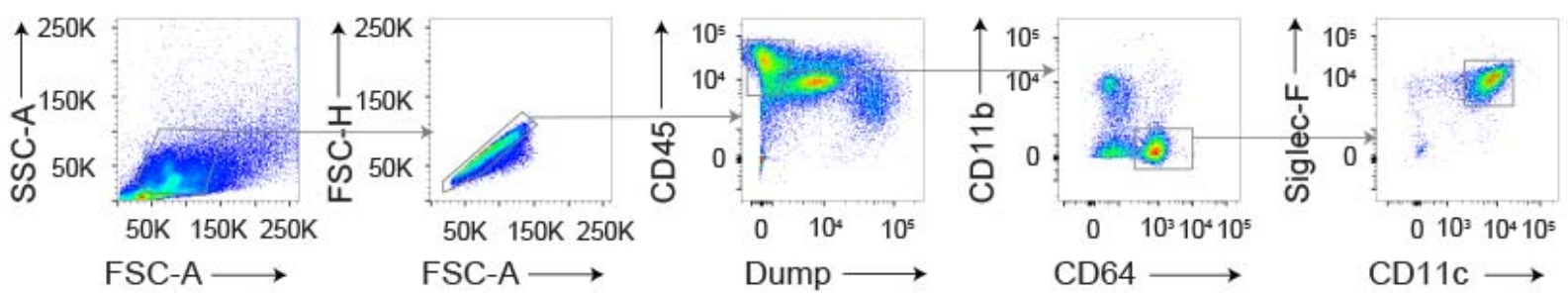

\section{f Gating strategy for brain microglia}

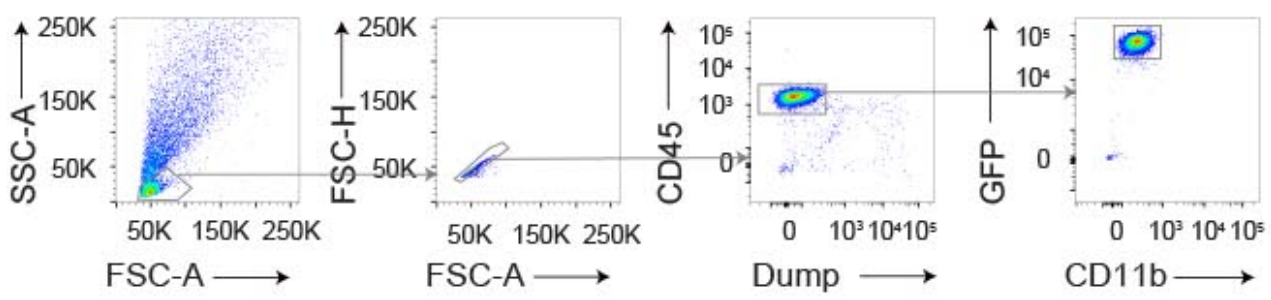


bioRxiv preprint doi: https://doi.org/10.1101/2022.02.09.479699; this version posted February 11, 2022. The copyright holder for this

preprint (which was not certified by peer review) is the author/funder, who has granted bioRxiv a license to display the preprint in perpetuity. It is made available under aCC-BY 4.0 International license.

Supplementary Figure 3: Gating strategy for the isolation of tissue resident macrophages

Shown are the gating strategies that allow the identification of (a) Langerhans cells in the skin, (b) splenic macrophages, (c) $\mathrm{C} \times 3 \mathrm{cr}^{+}$colonic macrophages, (d) $\mathrm{MHCll}^{+}$and $\mathrm{MHCll}^{-}$ $C \times 3 c r 1^{+}$heart macrophages, (e) alveolar macrophages and (f) microglia from the brain. 
ue - saggital section

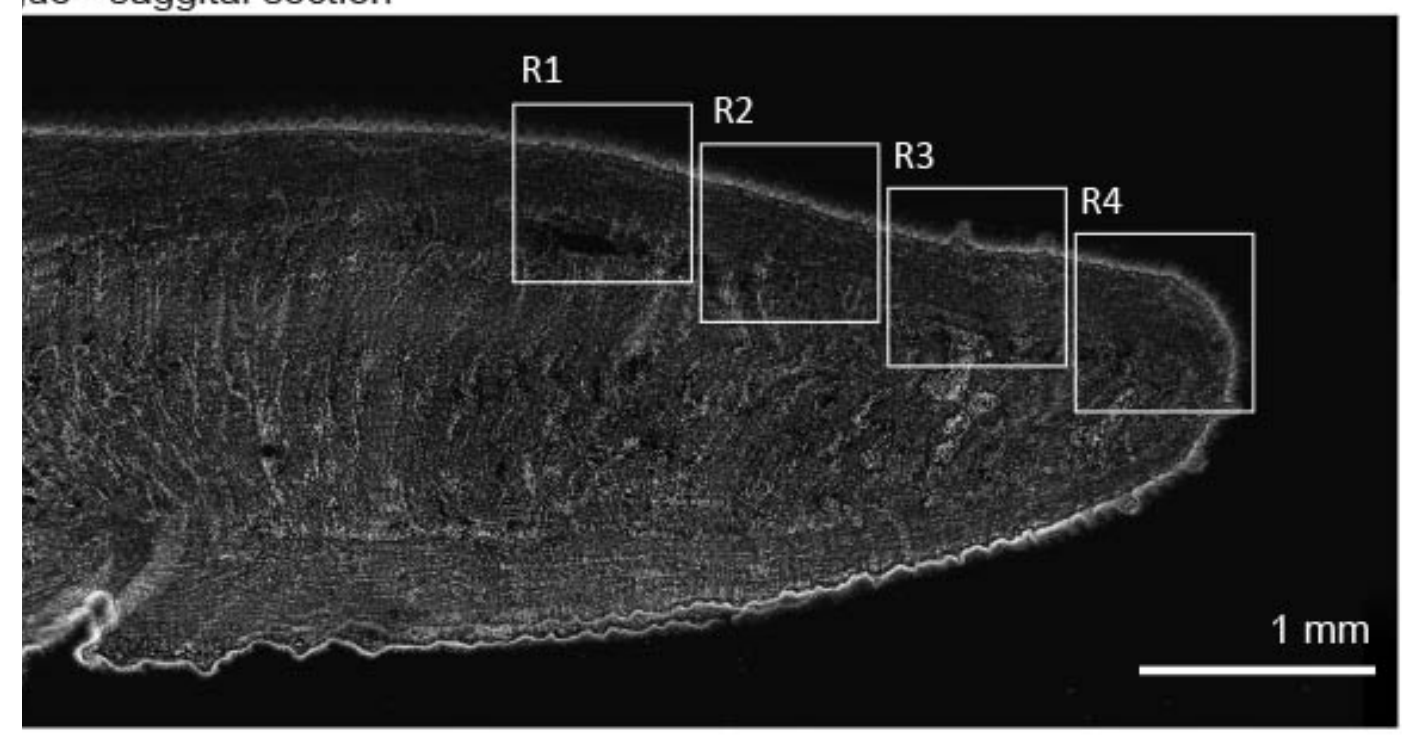

b

\section{Example R3}

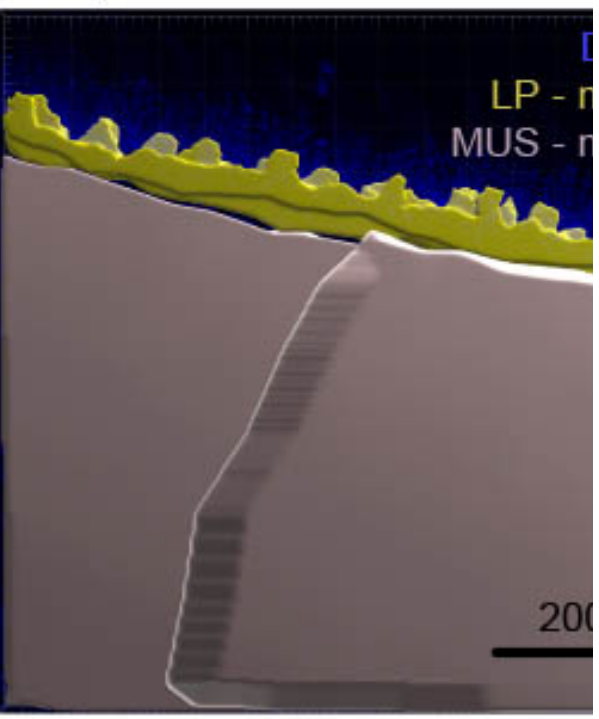

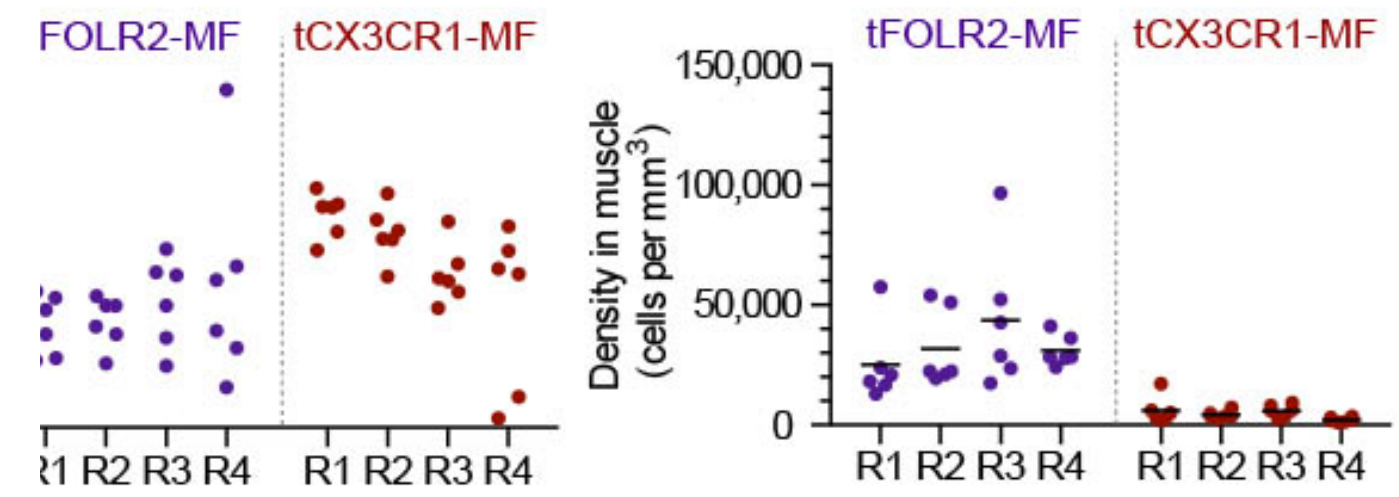

\section{Figure 4}


Supplementary Figure 4: Quantification of tongue macrophages

(a) Panoramic image of an adult tongue counterstained with DAPI (white). The insets represent different areas of the tongue that were quantified. (b) Imaris-based mask for the identification of epithelium, lamina propria and muscle. Analysis of cell density was performed within these areas. (c) Macrophage subset cell counts in the respective regions of the tongue as represented in (a). Shown is the density of cells $/ \mathrm{mm}^{3}$ in the lamina propria (left) and in the muscle (right). Each dot represents one independent animal. 
bioRxiv preprint doi: https://doi.org/10.1101/2022.02.09.479699; this version posted February 11, 2022. The copyright holder for this

preprint (which was not certified by peer review) is the author/funder, who has granted bioRxiv a license to display the preprint in perpetuity. It is made available under aCC-BY 4.0 International license.
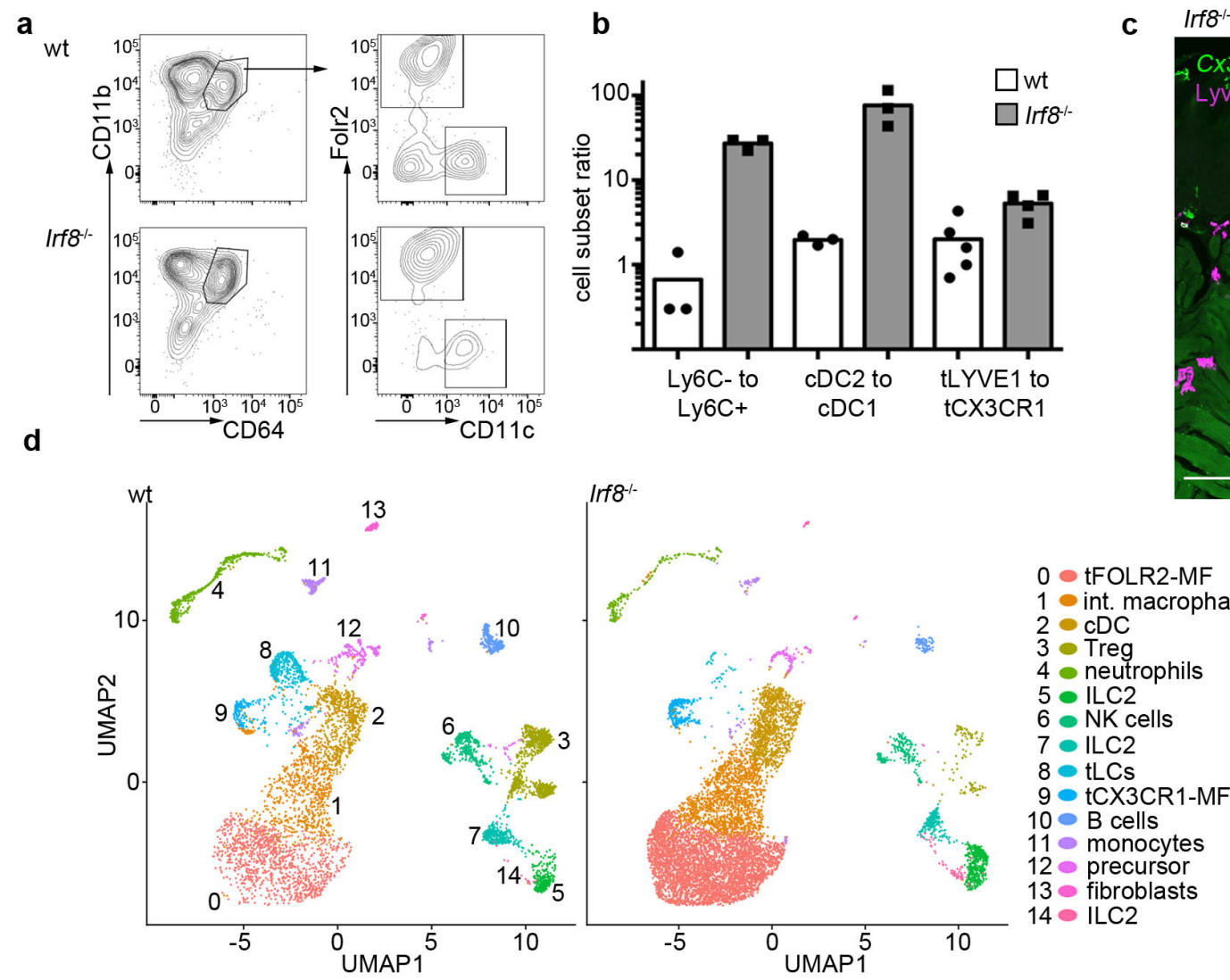

f

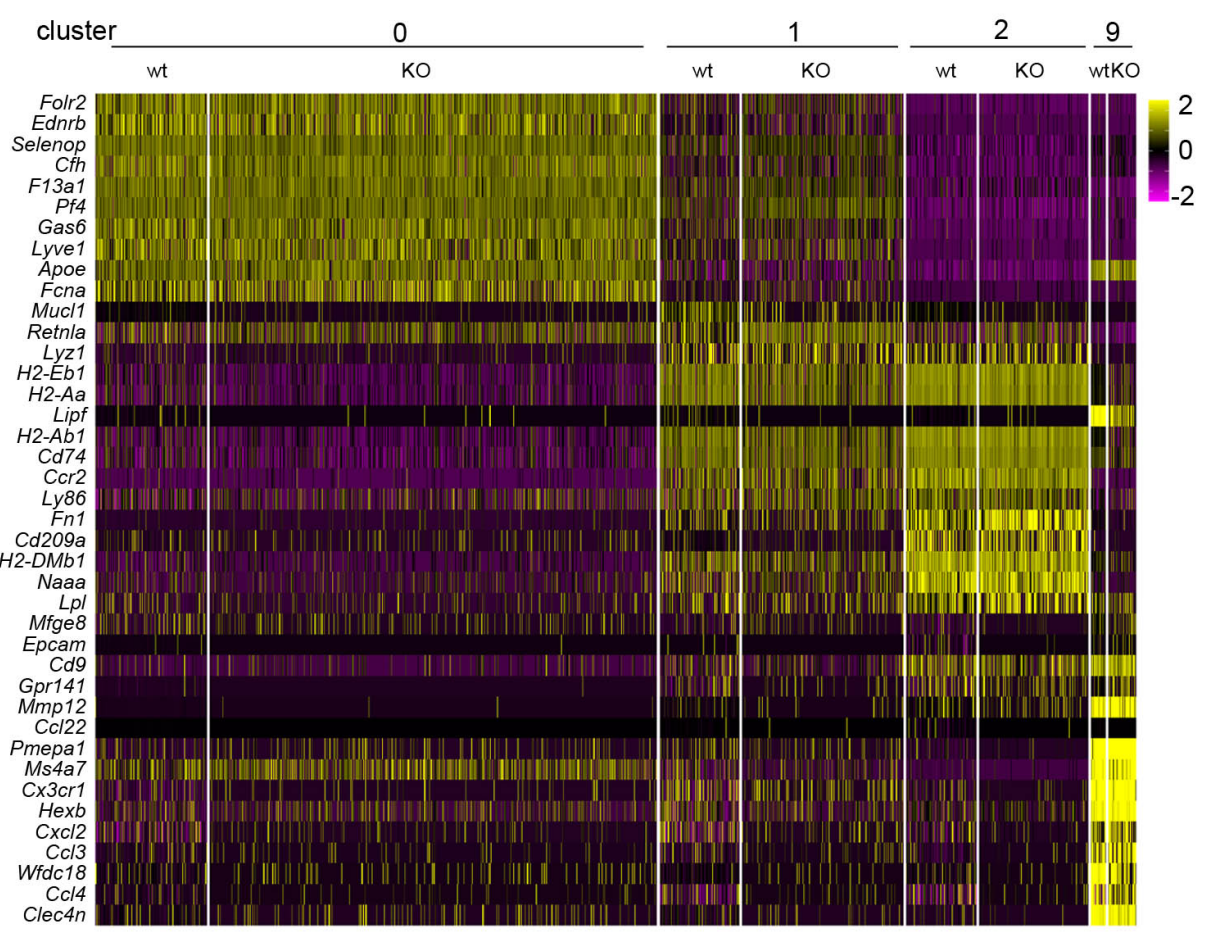

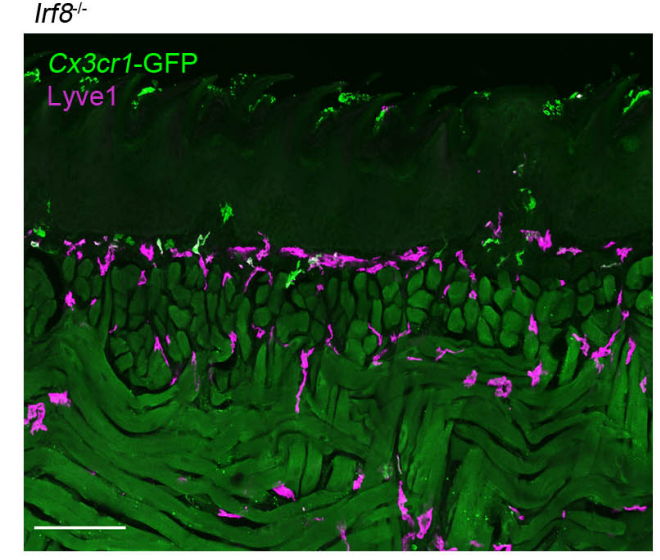

e
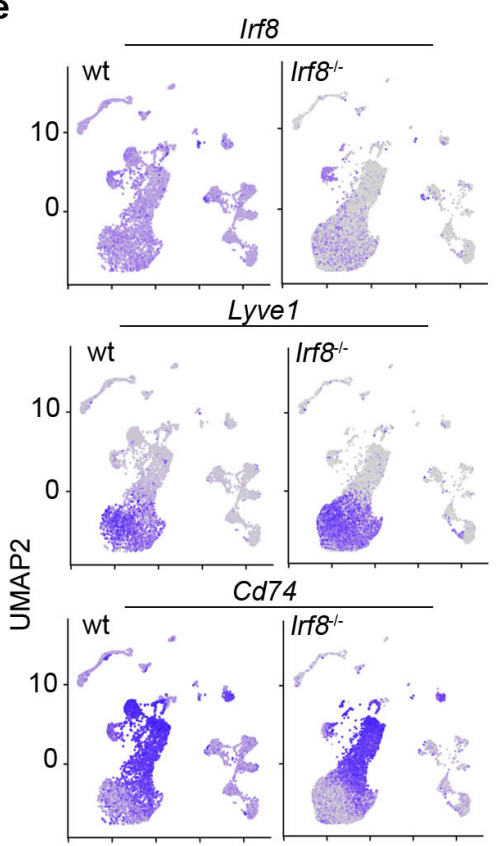

Cx3cr1

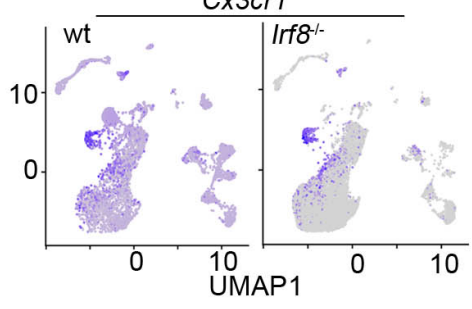

\section{Supplementary Figure 5}


Supplementary Figure 5: Irf8-deficiency does not affect the tongue leukocyte composition (a) Flow cytometry analysis of Irf8-deficient tongue leukocytes and their respective controls. The cells were pre-gated as $\mathrm{CD} 11 \mathrm{~b}^{+} \mathrm{CD}^{+} 4^{+}$. (b) Ratio analysis of $\mathrm{Ly}_{6 \mathrm{C}} \mathrm{C}^{-}$monocytes / $\mathrm{Ly}_{6 \mathrm{C}^{+}}$ monocytes, splenic cDC2 / cDC1 cells and tFOLR2-MF / tCX3CR1-MF isolated from WT ( $\mathrm{n}=$ 3-5) and Irf8-deficient mice $(n=3-4)$. Each dot represents one animal. The experiment was repeated twice. (c) Histological analysis of an adult Cx3cr1-GFP Irf8 ${ }^{-/-}$tongue reveals the presence of $\mathrm{GFP}^{+} \mathrm{tCX} 3 \mathrm{CR} 1-\mathrm{MF}$ in the lamina propria. Sections were stained with anti-GFP (green) and anti-LYVE1 (violet) antibodies. (d) 9047 CD45 ${ }^{+}$cells were profiled from adult Irf8deficient mice (pool of $n=5$ mice) by scRNA-seq. Shown are UMAP dimension reductions of WT (left) and Irf8-deficient CD45 ${ }^{+}$tongue cells (right). (e) Gene expression examples in wt and Irf8-deficient cells. Note that Irf8 transcripts can be detected on mRNA level in Irf8deficient mice since only exon 2 of the Irf8 gene is deleted in the Jackson strain 018298. (f) Heatmap of marker gene expression for clusters 0, 1, 2 and 9 in wildtype and Irf8-deficient cells. 
Supplementary data 1: Marker genes for the 19 identified clusters in the scRNA-seq experiments 1-4 together with the respective test statistics. Each cluster can be found in separated tabs. As test method we used MAST, the log2fc threshold was set to 0.25 and a Bonferroni mutiple testing correction was applied. We only considered genes, that were expressed in at least $20 \%$ of the cells in at least one of the groups. Note that cluster 11 is not represented due to low cell numbers and cluster 16 could only be detected in experiment 3 (LPS). These data sets belong to Fig. 1, 4 and 6.

Supplementary data 2: The file contains the average expression value for each cluster based on the normalized counts of the cells in the respective sample. Additionally, a column for each cluster indicates, whether a gene is a conserved marker for this cluster (see Suppl. Data 1). This data set belongs to Fig. 1.

Supplementary data 3: Core gene signatures of $\operatorname{cDC}(\operatorname{tab} 1)$, macrophages (tab 2), $\mathrm{cDC} 1$ (tab 3) and cDC2 (tab 4). The gene lists were derived from ${ }^{16,17}$. This data set belongs to Fig. 1.

Suppl. data 4: Represented are the full GO lists for the myeloid clusters $0,1,3,5,6,7$ and 10. This data set belongs to Fig. 1.

Suppl. data 5: This table includes the full bulk RNA-seq read counts for all isolated tissue resident macrophage populations that are shown in Fig. 2. Each subset is represented in a separate tab.

Suppl. data 6: Listed are the upregulated genes that could be extracted from the bulk RNAseq data. These genes were used for GO annotations represented in Fig. 2.

Suppl. data 7: Listed are all significant differential expressed genes between untreated and LPS-treated tFOLR2-MF (tab1) and tCX3CR1-MF (tab2).

Suppl. data 8: This $\mathrm{html}$ file shows the $3 \mathrm{D}$ representation of the postnatal day 3 UMAP represented in Fig. 6 